\title{
Limits to Arbitrage and Hedging: Evidence from Commodity Markets
}

\author{
Viral V. Acharya, Lars A. Lochstoer and Tarun Ramadorai*
}

January 17,2010

\begin{abstract}
Motivated by the literature on limits-to-arbitrage, we build an equilibrium model of commodity markets in which speculators are capital constrained, and commodity producers have hedging demands for commodity futures. Increases (decreases) in producers' hedging demand (speculators' risk-capacity) increase hedging costs via price-pressure on futures, reduce producers' inventory holdings, and thus spot prices. Consistent with our model, producers' default risk forecasts futures returns, spot prices, and inventories in oil and gas market data from 1980-2006, and the component of the commodity futures risk premium associated with producer hedging demand rises when speculative activity reduces. We conclude that limits to financial arbitrage generate limits to hedging by producers, and affect both asset and goods prices.
\end{abstract}

\footnotetext{
*Acharya is at London Business School, NYU-Stern, a Research Affiliate of CEPR and a Research Associate of the NBER. Lochstoer is at Columbia University. Ramadorai is at Said Business School, Oxford-Man Institute of Quantitative Finance, and CEPR. A part of this paper was completed while Ramadorai was visiting London Business School. Correspondence: Lars Lochstoer. E-mail: LL2609@columbia.edu. Mailing address: Uris Hall 405B, 3022 Broadway, New York, NY 10027. We thank Nitiwut Ussivakul, Prilla Chandra, Arun Subramanian, Virendra Jain, Krishan Tiwari and Ramin Baghai-Wadji for excellent research assistance, and seminar participants at the AFA 2010, ASAP Conference 2007, Columbia University, EFA 2009 (winner of Best Paper on Energy Markets, Securities and Prices Award), Princeton University, the UBC Winter Conference 2008, David Alexander, Sreedhar Bharath, Patrick Bolton, Pierre Collin-Dufresne, Joost Driessen, Erkko Etula, Gary Gorton, Jose Penalva, Helene Rey, Stephen Schaefer, Tano Santos, Raghu Sundaram and Suresh Sundaresan for useful comments. We are grateful to Sreedhar Bharath and Tyler Shumway for supplying us with their naive expected default frequency data.
} 


\title{
Limits to Arbitrage and Hedging: Evidence from Commodity Markets
}

\begin{abstract}
Motivated by the literature on limits-to-arbitrage, we build an equilibrium model of commodity markets in which speculators are capital constrained, and commodity producers have hedging demands for commodity futures. Increases (decreases) in producers' hedging demand (speculators' risk-capacity) increase hedging costs via price-pressure on futures, reduce producers' inventory holdings, and thus spot prices. Consistent with our model, producers' default risk forecasts futures returns, spot prices, and inventories in oil and gas market data from 1980-2006, and the component of the commodity futures risk premium associated with producer hedging demand rises when speculative activity reduces. We conclude that limits to financial arbitrage generate limits to hedging by producers, and affect both asset and goods prices.
\end{abstract}




\section{Introduction}

The neoclassical theory of asset pricing (Debreu (1959)) has been confronted by theory and evidence that highlight the numerous frictions faced by financial intermediaries in undertaking arbitrage (Shleifer and Vishny (1997)), and the consequent price effects of such frictions. These price effects appear to be amplified in situations in which financial intermediaries are substantially on one side of the market (say, for instance, when they bear the prepayment and default risk of households in mortgage markets, or when they provide catastrophe insurance to households, as in Froot (1999)). In this paper, we apply the "limits to arbitrage" view to the analysis of commodity futures markets, a significant sector of the economy that has recently experienced significant asset price movements as well as a renewed surge of attention from financial economists. In our theoretical model, commodity investment funds - speculators - are are constrained in their ability to deploy capital in the commodity futures market, and meet demands for hedging that come from commodity producing firms. The model, as well as our empirical analysis, reveals that this limit to arbitrage translates into "limits to hedging" experienced by producers, which in turn impacts real variables such as the spot commodity price.

More specifically, the limit on the risk-taking capacity of speculators implies a price impact of the hedging demand of risk-averse producers, who are naturally short commodity futures. This price impact constitutes a cost of hedging, which has consequences for the optimal inventory holding of commodity producers, and in turn, the commodity spot price. We derive implications of producer risk aversion and speculator capital constraints for the absolute and relative levels of futures and spot prices. To understand the comparative statics generated by the model, consider the following example: assume that producers as a whole need to hedge more by shorting futures contracts, say, on account of their rising default risk. Given that speculators are limited in their ability to take positions to satisfy this demand, it depresses futures prices and makes hedging more expensive. Consequently, producers scale back on holding inventory, releasing it into the market and depressing spot prices. Therefore, futures risk premia and expected percentage change in the spot price have a common driver - the hedging demand of producers. Due to this common driver, the model also predicts that the commodity convenience yield (or basis) should not be strongly related to commodity futures risk premia. Increases in speculators' capital constraints have similar effects.

To test the implications of our model, we employ data on spot and futures prices for heating oil, crude oil, gasoline and natural gas over the period 1980 to 2006. To identify changes in producers' risk aversion and hedging demand, we use movements in the default risk of commodity producing firms, an identification strategy driven by extant theoretical and empirical work on hedging. ${ }^{1}$ We

\footnotetext{
${ }^{1} \mathrm{~A}$ large body of theoretical work and empirical evidence on hedging has attributed managerial aversion to risk as a primary motive for hedging by firms (Amihud and Lev (1981), Tufano (1996), Acharya, Amihud and Litov (2007), and Gormley and Matsa (2008), among others); and has documented that top managers suffer significantly from firing and job relocation difficulties when firms default (Gilson (1989), Baird and Rasmussen (2006) and Ozelge
} 
employ three different aggregate measures of the default risk of oil and gas producers in our work: a balance-sheet based measure - the Zmijewski (1984) score; a measure that combines market data with balance-sheet data - the Moody's KMV's expected default frequency; and a pure market-based measure - the lagged three-year stock return of these producers. Our findings are as follows: First, commodity producer default risk is positively related to both aggregate and individual producer hedging demand. The latter is measured using information from the FAS 133 disclosures in annual and quarterly reports, while the former is measured as the net short positions of market participants classified as 'hedgers' by the Commodity Futures Trading Commission (CFTC). Second, an increase in the default risk of producers forecasts an increase in the excess returns on short-term futures of these commodities. The effect is robust to business-cycle conditions and economically significant: a one standard deviation increase in the aggregate commodity sector default risk is on average associated with a $4 \%$ increase in the respective commodity's quarterly futures risk premium. ${ }^{2}$ Third, the effect of the default risk of producers on futures risk premia is greater in periods with higher (conditional) volatility of commodity prices, consistent with such periods being associated with greater risk of commodity stock outs and a lower risk appetite in the financial intermediation sector. Fourth, we find that the fraction of the futures risk premium attributable to producers' default risk is higher in periods in which broker-dealer balance-sheets and the assets under management of commodity-focused funds are shrinking (these two measures of speculator risk appetite also predict futures risk premia, consistent with our model). Finally, as producer default risk increases, our model predicts that producers will hold less inventory, depressing current spot prices. This prediction is also confirmed in the data - increases in the default risk of oil and gas producers predict both lower inventory and higher spot returns.

We verify that our results are driven by changes in producer hedging demand in a number of ways. First, we employ a "matching" approach. In particular, we separate the sample of producers into those firms that hedge commodity price exposure using derivatives (identified by their FAS 133 disclosures between 1998-2006), versus those that do not hedge. We show that our results are driven only by measures of aggregate hedging demand derived from the firms that hedge. Second, we account for the possibility that default risk of commodity producers may be related to businesscycle conditions that also drive risk premiums. In particular, we employ controls in our forecasting regressions, in the form of variables commonly employed to predict the equity premium, such as changes in forecasts of GDP growth, the risk-free rate, the term spread, and the aggregate default spread, and confirm that our results are unaffected by the introduction of these controls. Third, from the set of commodity firms that are included in our Crude Oil measures, we separate out pure play refiners from those that extract (or extract and refine) the commodity. Since refiners use crude

(2007)). Fehle and Tsyplakov (2005) argue, both theoretically and empirically, that firms hedge more actively when default risk is higher.

${ }^{2}$ Futures risk premia are identified through standard forecasting regressions as in, e.g., Fama and French (1987). 
oil as an input, their hedging demand is likely to be in the opposite direction to that of producers - we verify this differential effect in the data. Finally, we employ controls that are commodity specific, such as the basis, inventory, lagged futures return, and the realized variance of futures returns in our specifications. This is to control for the possibility that producer default risk - an endogenous variable - may also be related to supply uncertainty, in the form of the likelihood of inventory stock-outs or other production shocks. Our model predicts that such supply uncertainty is related to the variance of the commodity price, but that increases in producer risk aversion should have effects as outlined earlier, even after controlling for this effect. The empirics confirm that default risk, our proxy for producer risk aversion, continues to explain futures risk premia after the introduction of these controls, indeed, there is an interactive effect of this predictive power with realized futures return variance as predicted by the model. To summarize, our model implies that limits to arbitrage generate limits to hedging for firms in the real economy. Consequently, factors that capture time-variation in such limits have predictive power for asset prices and affect outcomes in underlying product markets (spot prices and inventories). Our empirical results are consistent with the implications of the model and robust to a number of alternative explanations.

The remainder of the introduction relates our paper to the literature. Section 2 introduces our model. Section 3 presents our empirical strategy. Section 4 establishes the link between the hedging demand of commodity producers and measures of their default risk at the individual firm level. Section 5 discusses our main, aggregate empirical results. Section 6 concludes.

Related Literature. There are two classic views on the behavior of commodity forward and futures prices. The Theory of Normal Backwardation (Keynes (1930)), states that speculators, who take the long side of a commodity futures position, require a risk premium for hedging the spot price exposure of producers (an early version of the "limits to arbitrage" argument). The risk premium on long forward positions is thus increasing in the amount of demand pressure from hedgers and should be related to observed hedger and speculator positions in the commodity forward markets. Carter, Rausser and Schmitz (1983), Chang (1985), Bessembinder (1992), and de Roon, Nijman, and Veld (2000) empirically link this "hedging pressure" to futures excess returns, the basis and the convenience yield, as evidence in support of this theory.

The Theory of Storage (Kaldor (1939), Working (1949), and Brennan (1958)), on the other hand, postulates that forward prices are driven by optimal inventory management. In particular, this theory introduces the notion of a convenience yield to explain why anyone would hold inventory in periods in which spot prices are expected to decline. Tests of the theory include Fama and French (1987) and Ng and Pirrong (1994). In more recent work, Routledge, Seppi and Spatt (2000) introduce a forward market into the optimal inventory management model of Deaton and Laroque (1992) and show that time-varying convenience yields, consistent with those observed in the data, can arise even in the presence of risk-neutral agents. ${ }^{3}$

\footnotetext{
${ }^{3}$ There is a large literature on reduced form, no-arbitrage modeling of commodity futures prices (e.g., Brennan
} 
The two theories are not mutually exclusive. A time-varying risk premium on forwards is consistent with optimal inventory management if producers are not risk-neutral or face (say) bankruptcy costs; and speculator capital is not unlimited, as in our model. In the data, we find that hedgers are net short forwards on average, while speculators are net long, which indicates that producers do have hedging demands. In support of this view, Haushalter (2000, 2001) surveys 100 oil and gas producers over the 1992 to 1994 period and finds that close to 50 percent of them hedge, in the amount of approximately a quarter of their production each year. In a recent paper, Gorton, Hayashi, and Rouwenhorst (2007) provide evidence that futures risk premia are related to inventory levels. Consistent with their findings, our model also predicts that inventory should forecast commodity futures returns. In our model, this results is driven by the interaction between capital-constrained speculators and producer hedging demand, proxied by measures of producer default risk. Our empirical contribution is to identify that this default risk measure helps to explain commodity spot prices, risk premia, CFTC hedging pressure measures and inventory levels.

In closely related work, Hirshleifer $(1988,1989,1990)$ considers the interaction between hedgers and arbitrageurs. In particular, Hirshleifer (1990) observes that in equilibrium there must be a friction to investing in commodity futures in order for hedging demand to affect prices and quantities. In our model, this friction arises due to limited movement of capital, motivated by the 'limits to arbitrage' literature, and hedging demand of producers, motivated by a principal-agent problem as the commodity firm is ultimately owned by the consumers. Furthermore, our analysis, unlike Hirshleifer's, is also empirical. As a useful consequence, in addition to providing evidence for our model, we are able to confirm many of the propositions of Hirshleifer's $(1988,1989,1990)$ theoretical models, using a different approach than that in Bessembinder (1992). Another related paper is by Bessembinder and Lemmon (2002), who show that hedging demand affects spot and futures prices in electricity markets when producers are risk averse. They highlight that the absence of storage is what allows for predictable intertemporal variation in equilibrium prices. We show in this paper that the price impact can arise even in the presence of storage in the oil and gas markets.

Finally, it has proven difficult to explain the unconditional risk premiums on commodity futures using traditional asset pricing theory (see Jagannathan, (1985) for an earlier effort). Although conditional risk premiums on commodity futures do appear to be reliably non-zero (see Bessembinder (1992)), Bessembinder and Chan (1992) document that the forecastability of price changes in commodity futures is based on different asset pricing factors as compared to equity markets. Furthermore, in a recent paper, Tang and Xiong (2009) show that the correlation between commodity and equity markets increases in the amount of speculator capital flowing to commodity markets. These results are consistent with our assumption of time-varying market segmentation between equity and commodity markets.

(1991), Schwartz (1997), Cassasus and Collin-Dufresne (2005)). General equilibrium models of commodity pricing include Cassasus, Collin-Dufresne, and Routledge (2009), and Johnson (2009). 


\section{The Model}

We present a two-period model of commodity spot and futures price determination that includes optimal inventory management, as in Deaton and Laroque (1992), and hedging demand, similar to the models of Anderson and Danthine (1980, 1983) and Hirshleifer (1988, 1990). There are three types of agents in the model: (1) consumers, whose demand for the spot commodity along with the equilibrium supply determine the commodity spot price; (2) commodity producers, who manage profits by optimally managing their inventory and by hedging with commodity futures; and (3) speculators, whose demand for commodity futures, along with the futures hedging demand of producers, determine the commodity futures price. ${ }^{4}$

\subsection{Consumption, Production and the Spot Price}

Let commodity consumers' inverse demand function be given by:

$$
S_{t}=\omega\left(\frac{A_{t}}{Q_{t}}\right)^{1 / \varepsilon},
$$

where $S_{t}$ is the commodity spot price, $Q_{t}$ is the equilibrium commodity supply, $A_{t}$ is the consumption of other goods, and $\omega$ and $\varepsilon$ are positive constants. This inverse demand function obtains if the representative agent has CES utility over the two goods $(A$ and $Q$ ) with an intratemporal elasticity of substitution equal to $\varepsilon$. In the Appendix, we argue that the main predictions of our model presented here are robust to a general equilibrium setting where this inverse demand function is derived endogenously. In the partial equilibrium setting considered here, however, $A_{t}$ represents an exogenous demand shock, which we assume is lognormally distributed with $E\left[\ln A_{t}\right]=\mu$ and $\operatorname{Var}\left[\ln A_{t}\right]=\sigma^{2}$. This shock captures changes in demand arising from sources such as technological changes in the production of substitutes and complements for the commodity, weather conditions, or other shocks that are not explicitly accounted for in the model.

Let aggregate inventory and production be denoted $I_{t}$ and $G_{t}$, respectively. Further, let $\delta$ be the cost of storage; that is, individual producers can store $i$ units of the commodity at $t-1$ yielding $(1-\delta) i$ units at $t$, where $\delta \in(0,1)$. The commodity spot price is determined by market clearing, which demands that incoming aggregate inventory and current production, $G_{t}+(1-\delta) I_{t-1}$, equals current consumption and outgoing inventory, $Q_{t}+I_{t}$.

\footnotetext{
${ }^{4}$ We model consumers of the commodity as operating only in the spot market. This is an abstraction, which does not correspond exactly with the evidence - for instance airlines have been known periodically to hedge their exposure to the price of jet fuel (by taking long positions in the futures market). In the empirical section, we show that our results are not affected by controlling for a measure of consumers' hedging demand. Furthermore the CFTC data on hedger positions indicates that speculative capital (e.g., in hedge funds) has historically been allocated to long positions in commodity futures, indicating that the sign of net hedger demand for futures is consistent with our assumption.
} 


\subsection{Producers}

There are an infinite number of commodity producing firms in the model, with mass normalized to one. Each individual manager acts competitively as a price taker. The timing of managers' decisions in the model are as follows: In period 0, the firm stores an amount $i$ as inventory from its current supply, $g_{0}$, and so period 0 profits are simply $S_{0}\left(g_{0}-i\right)$. In period 0 , the firm also goes short a number $h_{p}$ of futures contracts, to be delivered in period 1. In period 1, the firm sells its current inventory and production supply, honors its futures contracts and realizes a profit of $S_{1}\left(i(1-\delta)+g_{1}\right)+h_{p}\left(F-S_{1}\right)$, where $F$ is the futures price and $g_{1}$ is supply in period 1.5

We assume that managers of commodity producing firms are risk averse - they maximize the value of the firm subject to a penalty for the variance of next period's earnings. This variance penalty generates hedging demand, and is a frequent assumption when modeling commodity producer behavior (for one recent example see Bessembinder and Lemmon (2002)). ${ }^{6}$ Writing $\Lambda$ for the marginal rate of substitution (pricing kernel) of equity holders in the economy, ${ }^{7}$ and $r$ for the risk-free rate, the managers' objective function is:

$$
\begin{aligned}
& \max _{\left\{i, h_{p}\right\}} S_{0}\left(g_{0}-i\right)+E\left[\Lambda\left\{S_{1}\left((1-\delta) i+g_{1}\right)+h_{p}\left(F-S_{1}\right)\right\}\right] \ldots \\
& \quad-\frac{\gamma_{p}}{2} \operatorname{Var}\left[S_{1}\left((1-\delta) i+g_{1}\right)+h_{p}\left(F-S_{1}\right)\right],
\end{aligned}
$$

subject to:

$$
i \geq 0 \text {. }
$$

The first order condition with respect to inventory holding $i$ yields:

$$
i^{*}(1-\delta)=\frac{(1-\delta) E\left[\Lambda S_{1}\right]-S_{0}+\lambda}{(1-\delta) \gamma_{p} \sigma_{S}^{2}}-g_{1}+h_{p}
$$

where $\lambda$ is the Lagrange multiplier on the inventory constraint and $\sigma_{S}^{2}$ is the variance of the period 1 spot price. As can be seen from Equation (3), managers use inventories to smooth demand shock. If, however, the current demand shock is sufficiently high, an inventory stock-out occurs (i.e., $\lambda>0$ ), and current spot prices can rise above expected future spot prices. In such a circumstance, firms

\footnotetext{
${ }^{5}$ Note that the production schedule, $g_{0}$ and $g_{1}$, is assumed to be pre-determined. The implicit assumption, which creates a role for inventory management, is that it is prohibitively costly to change production in the short-run.

${ }^{6}$ The literature on corporate hedging provides several justifications for this modeling choice. Hedging demand could result from managers being underdiversified, as in Amihud and Lev (1981) and Stulz (1984), or better informed about the risks faced by the firm (Breeden and Viswanathan (1990), and DeMarzo and Duffie (1995)). Managers could also be averse to variance on account of private costs suffered upon distress, as documented by Gilson (1989) for example, or the firm may face deadweight costs of financial distress, as argued by Smith and Stulz (1985). Aversion to earnings volatility can also be generated from costs of external financing as in Froot, Scharfstein, and Stein (1993).

${ }^{7}$ The setup implicitly assumes that the equity-holders cannot write a complete contract with the managers, on account of (for instance) incentive reasons as in Holmstrom (1979).
} 
wish to have negative inventory, but cannot. Thus, a convenience yield for holding the spot arises, as those who hold the spot in the event of a stock-out get to sell at a temporarily high price. This is the Theory of Storage aspect of our model. ${ }^{8}$ Importantly, inventory is increasing in the amount hedged in the futures market, $h_{p}$. That is, hedging allows the producer to hold more inventory as it reduces the amount of earnings variance that the producer would otherwise be exposed to. Thus, the futures market provides an important venue for risk sharing.

The first order condition for the number $h_{p}$ of futures contracts that the producer goes short is:

$$
h_{p}^{*}=i^{*}(1-\delta)+g_{1}-\frac{E\left[\Lambda\left(S_{1}-F\right)\right]}{\gamma_{p} \sigma_{S}^{2}},
$$

Note that if the futures price $F$ is such that $E\left[\Lambda\left(S_{1}-F\right)\right]=0$, there are no gains or costs to equity holders of the manager's hedging activity in terms of expected, risk adjusted profits. The producer will therefore simply minimize the variance of period 1 profits by hedging fully. In this case, the manager's optimal hedging strategy is independent of the degree of managerial risk aversion. This is a familiar result that arises by no-arbitrage in frictionless complete markets.

If, however, the futures price is lower than what is considered fair from the equity-holders' perspective (i.e., $E\left[\Lambda\left(S_{1}-F\right)\right]>0$ ), it is optimal for the producer to increase the expected profits by entering a long speculative futures position after having fully hedged the period 1 supply. In other words, in this situation, the hedge is costly due to perceived mispricing in the commodity market, and it is no longer optimal to hedge the period 1 price exposure fully. This entails shorting fewer futures contracts. Note that an increase in the manager's risk aversion $\gamma_{p}$ decreases this implicit speculative futures position, all else equal.

The Basis. The futures basis is defined as:

$$
\text { basis } \equiv \frac{S_{0}-F}{S_{0}}=y-\frac{r+\delta}{1-\delta},
$$

where $y$ is the convenience yield. Combining the first order conditions of the firm (Equations (3) and (4)), the convenience yield is given by:

$$
y=\frac{\lambda}{S_{0}} \frac{1+r}{1-\delta}
$$

The convenience yield can only differ from zero if the shadow price of the inventory constraint $(\lambda)$ is positive. In this case, the expected future spot price is low relative to the current spot price, and this results in the futures price also being low relative to the current spot price.

\footnotetext{
${ }^{8}$ In a multi-period setting, a convenience yield of holding the spot arises in these models even if there is no actual stock-out, but as long as there is a positive probability of a stock-out (see Routledge, Seppi, and Spatt (2000)).
} 
The basis is not a good measure of the futures risk premium when inventories are positive. Producers in the model can obtain exposure to future commodity prices in one of two ways - either by going long a futures contract, or by holding inventory. In equilibrium, the marginal payoff from these strategies must coincide. Thus, producers managing inventory enforce a common component in the payoff to holding the spot and holding the futures, with offsetting impacts on the basis. This prediction of the model is borne out in our empirical results, and is consistent with the findings of Fama and French (1987).

\subsection{Speculators}

Speculators take the long positions that offset producers' naturally short positions, and allow the market to clear. We assume that these speculators are specialized investment management companies, with superior investment ability in the commodity futures market (e.g., commodity hedge funds and investment bank commodity trading desks). As a consequence of this superior investment technology, investors in other financial assets (the equity-holders) only invest in commodity markets by delegating their investments to these specialized funds. As in Berk and Green (2004), the managers of these funds extract all the surplus of this activity and the outside investors only get their fair risk compensation. The payoff to the fund manager per long futures contract is therefore $E\left[\Lambda\left(S_{1}-F\right)\right]$, making the net present value for equity-holders of investing in a commodity fund zero, as dictated by no-arbitrage.

The commodity fund managers are assumed to be risk-neutral, but they are subject to capital constraints. These constraints could arise from costs of leverage such as margin requirements, as well as from value-at-risk (VaR) limits. We model these capital constraints as proportional to the variance of the fund's position, in the spirit of a VaR constraint, as in Danielsson, Shin, and Zigrand (2008). ${ }^{9}$ Commodity funds are assumed to behave competitively, and we assume the existence of a representative fund with objective function:

$$
\begin{gathered}
\max _{h_{s}} h_{s} E\left[\Lambda\left(S_{1}-F\right)\right]-\frac{\gamma_{s}}{2} \operatorname{Var}\left[h_{s}\left(S_{1}-F\right)\right] \\
\Downarrow \\
h_{s}^{*}=\frac{E\left[\Lambda\left(S_{1}-F\right)\right]}{\gamma_{s} \sigma_{S}^{2}},
\end{gathered}
$$

where $\gamma_{s}$ is the severity of the capital constraint, and $h_{s}$ is the aggregate number of long speculator

\footnotetext{
${ }^{9}$ Such a constraint is also assumed by Etula (2009) who finds empirical evidence to support the role of speculator capital constraints in commodity futures pricing. Gromb and Vayanos (2002) show in an equilibrium setting that arbitrageurs, facing constraints akin to the one we assume in this paper, will exploit but not fully correct relative mispricing between the same asset traded in otherwise segmented markets. Motivating such constraints on speculators, He and Xiong (2008) show that narrow investment mandates and capital immobility are natural outcomes of an optimal contract in the presence of unobservable effort on the part of the investment manager.
} 
futures positions. If commodity funds were not subject to any constraints (i.e., $\gamma_{s}=0$ ), the market clearing futures price would be the same as that which would prevail if markets were frictionless; i.e., such that $E\left[\Lambda\left[\left(S_{1}-F\right)\right]=0\right.$. In this case, the producers would simply hedge fully, as discussed previously, and the futures risk premium would be independent of the level of managerial risk aversion. With $\gamma_{s}, \gamma_{p}>0$, however, the equilibrium futures price will in general not satisfy the usual relation, $E\left[\Lambda\left(S_{1}-F\right)\right]=0$, as the risk-adjustment implicit in the speculators' objective function is different from that of the equity-holders.

\subsection{Equilibrium}

The futures contracts are in zero net supply and therefore $h_{s}=h_{p}$, in equilibrium. From equations (4) and (8) we obtain:

$$
E\left[\Lambda\left(S_{1}-F\right)\right]=\frac{\gamma_{s} \gamma_{p}}{\gamma_{s}+\gamma_{p}} \sigma_{S}^{2} Q_{1}
$$

where the variance of the spot price is $\sigma_{S}^{2} \equiv \omega^{2} Q_{1}^{-2 / \varepsilon}\left(e^{(\sigma / \varepsilon)^{2}}-1\right) e^{2 \mu / \varepsilon+(\sigma / \varepsilon)^{2}}$, and where period 1 supply is $Q_{1}=I^{*}(1-\delta)+g_{1}$. From the expression for the basis, $\left(S_{0}-\lambda\right) \frac{1+r}{1-\delta}=F$. We have that:

$$
E\left[\Lambda S_{1}\left(I^{*}\right)\right]-\left(S_{0}\left(I^{*}\right)-\lambda\left(I^{*}\right)\right) /(1-\delta)=\frac{\gamma_{s} \gamma_{p}}{\gamma_{s}+\gamma_{p}} k Q_{1}\left(I^{*}\right)^{1-2 / \varepsilon}
$$

where $k \equiv \omega^{2}\left(e^{(\sigma / \varepsilon)^{2}}-1\right) e^{2 \mu / \varepsilon+(\sigma / \varepsilon)^{2}}$. Equation (10) implicitly gives the solution for $I^{*}$. Since $F=\left(S_{0}\left(I^{*}\right)-\lambda\left(I^{*}\right)\right) \frac{1+r}{1-\delta}$, the equilibrium supply of short futures contracts can be found using equation (4).

\subsection{Model Predictions}

Equation (9) can be rewritten in terms of the futures risk premium. In particular, defining $\sigma_{f}=$ $\sigma_{S} / F$ as the standard deviation of the futures return, $\frac{S_{1}-F}{F}$, we have that:

$$
E\left[\frac{S_{1}-F}{F}\right]=-(1+r) \operatorname{Corr}\left(\Lambda, S_{1}\right) \operatorname{Std}(\Lambda) \sigma_{f}+\frac{\gamma_{p} \gamma_{s}}{\gamma_{p}+\gamma_{s}}(1+r) \sigma_{f}^{2} F Q_{1}
$$

The first term on the right hand side is the usual risk adjustment term due to covariance with the equity-holders' pricing kernel. However, the the producers and the speculators are the marginal investors in this market, rather than the equity-holders. The second term, which arises due to the combination of limits to arbitrage and producer hedging demand, has four components: $F Q_{1}$, the forward dollar value of the hedging demand, $\sigma_{f}^{2}$, the variance of the futures return, $\gamma_{p}$, producers' risk aversion, and $\gamma_{s}$, speculator risk aversion. Note that Equation (11) holds for any consumer 
preferences (inverse demand functions). ${ }^{10}$

Comparative Statics. We are interested in comparative statics with respect to producers' propensity to hedge, $\gamma_{p}$ (which we refer to henceforth as producers' fundamental hedging demand), and the degree of the capital constraint on speculators, $\gamma_{s}$. The proof of the following Proposition is relegated to the Appendix, and we only give the economic intuition for the results in this section.

Proposition 1 The futures risk premium and the expected spot price return are increasing in producers fundamental hedging demand, $\gamma_{p}$ :

$$
\frac{d}{d \gamma_{p}} \frac{E\left[S_{1}-F\right]}{F}>0 \quad \text { and } \quad \frac{d}{d \gamma_{p}} \frac{E\left[S_{1}-S_{0}\right]}{S_{0}}>0
$$

where the latter only holds if there is not a stock-out. In the case of a stock-out, $\frac{d}{d \gamma_{p}} \frac{E\left[S_{1}-S_{0}\right]}{S_{0}}=0$.

The futures risk premium and the expected spot price return are increasing in the severity of speculators' capital constraints, $\gamma_{s}$ :

$$
\frac{d}{d \gamma_{s}} \frac{E\left[S_{1}-F\right]}{F}>0 \quad \text { and } \quad \frac{d}{d \gamma_{s}} \frac{E\left[S_{1}-S_{0}\right]}{S_{0}}>0
$$

where the latter only holds if there is not a stock-out. In the case of a stock-out, $\frac{d}{d \gamma_{s}} \frac{E\left[S_{1}-S_{0}\right]}{S_{0}}=0$.

The optimal inventory is decreasing in both producer and speculator hedging demand, unless there is a stock-out.

The intuition for these results is as follows. When producers' fundamental hedging demand $\left(\gamma_{p}\right)$ increases, the manager's sensitivity to the risk of holding unhedged inventory increases. In response to this, the manager reduces inventory and increases the proportion of future supply that is hedged. The former means that more of the commodity is sold on the spot market, which depresses current spot prices and raises future spot prices. The latter leads to a higher variance-adjusted demand for short futures contracts, which is accommodated by increasing the futures risk premium. An increase in speculator capital constraints, $\gamma_{s}$, has similar effect. The cost of hedging now increases as the speculators require a higher compensation per unit of risk. The direct effect of this is to decrease the number of short futures positions. However, this leaves the producer more exposed to

\footnotetext{
${ }^{10}$ Since producer hedging demand and limits to arbitrage both affect the optimal supply (inventory) of the commodity, the volatility of futures returns is also affected, meaning that the frictions assumed in the commodity market also show up in the standard risk adjustment (the covariance term). Thus, there is a component of the futures risk premium that originates from limits to arbitrage and hedging demand that cannot be separately observed from the standard risk adjustment. Symmetrically, if the volatility and mean of the demand shocks change, this is reflected in the volatility of the futures return which also shows up in the futures risk premium term due to hedging demand and limits to arbitrage. In the Appendix, we further discuss the interaction between the frictions proposed here and the standard risk adjustment in the context of a general equilibrium model where the pricing kernel and the inverse demand function are derived endogenously.
} 
period 1 spot price risk, and to mitigate this effect, optimal inventory also decreases. In a stock-out, the inventory is constant (at zero) and consequently so are the expected spot price and its variance. In that case, the only effect of an increase in producer (or speculator) risk aversion is the direct effect on the futures risk premium, as the marginal cost of hedging increases.

To evaluate the likely magnitudes of the effect of the model's frictions and to illustrate the model results, we calibrate the model using key moments of the data: in particular, the volatility of the commodity futures returns, commodity expenditure relative to aggregate endowment (GDP) and aggregate endowment growth, as well as the mean and volatility of the equity market pricing kernel. The details of the calibration are given in the Appendix.

The severity of the model's frictions are increasing in the variance aversion of producers and speculators, $\gamma_{p}$ and $\gamma_{s}$. The variation in these quantities is shown in the two top graphs of Figure 1 as the producers' cost of hedging and the Sharpe ratio earned by speculators, where $\gamma_{p}$ is on the horizontal axis and $\gamma_{s}$ is shown as a dashed line for high speculator risk aversion and a solid line for low speculator risk aversion. The remainder of the plots in Figure 1 shows that the spot and futures risk premiums are indeed increasing in producer and speculator risk aversion, while inventory is decreasing. The calibration implies economically significant variation in both spot and futures risk premiums. In particular, for high speculator risk aversion (corresponding to their earning a quarterly Sharpe ratio of about 0.25) and high hedging demand (corresponding to a loss of about $0.8 \%$ of firm value due to hedging), the abnormal quarterly futures risk premium is about $6 \%$, whereas for low producer hedging demand and speculator risk aversion (Sharpe ratio of about 0.05 and loss from hedging of about $0.1 \%$ of firm value), the abnormal futures risk premium is less than $1 \%$. At the same time, the impact on inventory is about a $1 \%$ to $9 \%$ change in the level. The effect on expected percentage spot price changes is about the same as for the futures, since the cost of carry relation holds when there is no stock-out. In sum, reasonable levels of the costs of hedging and required risk compensation leads to economically significant abnormal returns in the futures market, and concomitant changes in inventory and spot prices.

Figure 1 also illustrates an intuitive interaction between speculator risk tolerance and producer hedging demand. In particular, the response of the abnormal futures risk premium to changes in producer hedging demand is smaller when speculator risk tolerance is high. These are times when speculators are willing to meet the hedging demand of producers with small price concessions. If, conversely, speculators are more risk averse, the price concession required to meet an additional unit of hedging demand is high.

\section{Empirical Strategy}

In our empirical analysis we test the main predictions of the model, as laid out in Proposition 1. To do so, we need proxies for $\gamma_{p}$ and $\gamma_{s}$ - the fundamental hedging demand and risk appetite of 
producers and speculators, respectively. Clearly, from Equation (11), to identify time-variation in the futures risk premium from hedging pressure and limits to speculative capital, we must control for the covariance of the futures return with the equity pricing kernel. We therefore apply a substantial set of controls and robustness checks in the empirical analysis in order to establish that our findings arise on account of producer hedging demand and limited arbitrage capital.

\subsection{Commodity Producer Sample}

To construct proxies for fundamental producer hedging demand, we employ data on commodity producing firms' accounting and stock returns from the CRSP-Compustat database. The use of Compustat data limits the study to the oil and gas markets as these are the only commodity markets where there is a large enough set of producer firms to create a reliable time-series of aggregate commodity sector producer hedging demand. Our empirical analysis thus focuses on four commodities: crude oil, heating oil, gasoline, and natural gas. The full sample of producers includes all firms with SIC codes 1310 and 1311 (Petroleum Refiners) and 2910 and 2911 (Crude Petroleum and Gas Extraction). ${ }^{11}$ The total sample of producers consists of 525 firms with quarterly data going back to 1974 for some firms. We also use data on firms' explicitly disclosed hedging activities from accounting statements available in the EDGAR database from 1998 to 2006.

\subsection{Proxying for Fundamental Hedging Demand}

"The amount of production we hedge is driven by the amount of debt on our consolidated balance sheet and the level of capital commitments we have in place."

- St. Mary Land \& Exploration Co. in their 10-K filing for 2006.

In the model, we refer to the variance aversion of the producers, $\gamma_{p}$, as producers' fundamental hedging demand. In the empirical analysis, we propose that variation in the aggregate level of $\gamma_{p}$ can be proxied for, using measures of aggregate default risk for the producers of the commodity. There are both empirical and theoretical motivations for this choice, which we discuss below. In addition, we show in the following section that the available micro-evidence of individual producer hedging behavior in our sample supports this assumption.

The driver of hedging demand that we focus on is managerial aversion to distress and default. In particular, we postulate that managers act in an increasingly risk averse manner as the likelihood of distress and default increases. Amihud and Lev (1981) and Stulz (1984) propose general aversion of managers to variance of cash flows as a driver of hedging demand, the rationale being that while

\footnotetext{
${ }^{11}$ These SIC classifications, however, are rather coarse: firms designated as "Petroleum Refiners" (e.g., Exxon) often also engage in extraction, and vice versa. In our robustness checks below, we separate out pure play refiners (as identified from their annual statements) from firms that engage in production, and separately evaluate the effects of default risk measures from each of these groups.
} 
shareholders can diversify across firms in capital markets, managers are significantly exposed to their firms' cash-flow risk due to incentive compensation as well as investments in firm-specific human capital. Empirical evidence has demonstrated that managerial turnover is indeed higher in firms with higher leverage and deteriorating performance: e.g., Coughlan and Schmidt (1985), Warner et al. (1988) and Weisbach (1988) provide evidence that top management turnover is predicted by declining stock market performance. Gilson (1989) refines this evidence, and examines the role of defaults and leverage. He first finds that management turnover is more likely following poor stock-market performance, and that firms that are highly leveraged or in default on their debt experience higher top management turnover than their counterparts. Gilson further documents that following their resignation from firms in default, managers are not subsequently employed by another exchange-listed firm for at least three years - consistent with managers experiencing large personal costs when their firms default. Finally, Haushalter $(2000,2001)$ in a survey of one hundred oil and gas firms over the 1992 to 1994 period, uncovers that their propensity to hedge is highly correlated with their financing policies as well as their level of assets in place. In particular, he finds that the oil and gas producers in his sample that use more debt financing also hedge a greater fraction of their production, and he interprets this result as evidence that companies hedge to reduce the likelihood of financial distress.

Given this theoretical and empirical motivation, we employ both balance-sheet and marketbased measures of default risk as our empirical proxies for the cost of external finance. The balancesheet based measure we employ is the Zmijewski (1984) score. This measure is positively related to default risk and is a variant of Altman's (1968) Z-score, and the methodology employed to calculate the Zmijewski-score was developed by identifying the firm-level balance-sheet variables that help to "discriminate" whether a firm is likely to default or not. The market-based measures we employ are first (following Gilson (1989)), the rolling three-year average stock return of commodity producers, and second, the naive expected default frequency (or naive EDF) computed by Bharath and Shumway (2008).

Each firm's Zmijewski-score is calculated as:

$$
\begin{aligned}
\text { Zmijewski-score } & =-4.3-4.5 * \text { NetIncome/TotalAssets }+5.7 * \text { TotalDebt/TotalAssets } \\
& -0.004 * \text { CurrentAssets/CurrentLiabilities. }
\end{aligned}
$$

Each firm's rolling three-year average stock return, writing $R_{i t}$ for the cum-dividend stock return for a firm $i$ calculated at the end of month $t$, is calculated as:

$$
\text { ThreeYearAvg } g_{i, t}=\frac{1}{36} \sum_{k=0}^{35} \ln \left(1+R_{i, t-k}\right)
$$


Finally, we obtain each firm's naive EDF. The EDF from the KMV-Merton model is computed using the formula:

$$
E D F=\Phi\left(-\left(\frac{\ln (V / F)+\left(\mu-0.5 \sigma_{V}^{2}\right) T}{\sigma_{V} \sqrt{T}}\right)\right)
$$

where $V$ is the total market value of the firm, $F$ is the face value of the firm's debt, $\sigma_{V}$ is the volatility of the firm's value, $\mu$ is an estimate of the expected annual return of the firm's assets, and $T$ is the time period (in this case, one year). Bharath and Shumway (2008) compute a 'naive' estimate of the EDF, employing certain assumptions about the variable used as inputs into the formula above. We use their estimates in our empirical analysis. ${ }^{12}$ Of the set of 525 firms, we have naive EDF estimates for 435 firms.

In the next section, we first confirm Haushalter's $(2000,2001)$ results in our sample of firms i.e., that our default risk measures are indeed related to individual producer firms' hedging activity. We then aggregate these firm-specific measures within each commodity sector to obtain aggregate measures of fundamental producer hedging demand, which are used to test the pricing implications of the model. To arrive at these aggregate measures of producer's hedging demand, we construct an equal-weighted Zmijewski-score, 3-year lagged stock returns, and Naive EDF from the producers in each commodity sector. While our sample of firms goes back until 1974, the number of firms in any given quarter varies with data availability at each point in time. There are, however, always more than 10 firms underlying the aggregate hedging measure in any given quarter. Figures $2 a$ and $2 b$ show the resulting time-series of aggregate Zmijewski-score, 3-year lagged return, and Naive EDF for the Crude Oil, Heating Oil, and Gasoline sectors, as well as for the Natural Gas sector. For ease of comparison, the series have been normalized to have zero mean and unit variance. All the measures are persistent and stationary (the latter is confirmed in unreported unit root tests for all the measures). As expected, the aggregate Zmijewski-scores and Naive EDF's are positively correlated, while the aggregate 3-year producer lagged stock return measure is negatively correlated with these measures. Table 2 reports the mean, standard deviation and quarterly autocorrelation of the aggregate hedging measures. The reason that these summary statistics are different for Crude Oil, Heating Oil, and Gasoline is that the futures returns data are of different sample sizes across the commodities.

\section{Producers' Hedging Behavior}

While the main tests in the paper concern the relationship between spot and futures commodity prices and the commodity sector's aggregate fundamental hedging demand, we first investigate the available micro evidence of producer hedging behavior. Haushalter (2000, 2001) provides useful evidence of the cross-sectional determinants of hedging behavior among oil and gas firms, but his

\footnotetext{
${ }^{12}$ We thank Sreedhar Bharath and Tyler Shumway for providing us with these estimates.
} 
evidence pertains to a smaller sample than ours, over the period from 1992 to $1994 .{ }^{13}$ A natural question for our purposes is to what extent the oil and natural gas producing firms in our sample actually do engage in hedging activity, and if so, in which derivative instruments and using what strategies. In this section, we use the publicly available data from firm accounting statements in the EDGAR database to ascertain the extent and nature of individual commodity producer hedging behavior.

\subsection{Summary of Producer Hedging Behavior}

The EDGAR database has available quarterly or annual statements for 231 of the 525 firms in the sample. In part, the smaller EDGAR sample is due to the fact that derivative positions are only reported in accounting statements, in our sample, from 1998 onwards. ${ }^{14}$ We determine whether or not each firm uses derivatives for hedging commodity price exposure by reading at least two quarterly or annual reports per firm. Panel A in Table 1 shows that out of the 231 firms, there are 172 that explicitly state that they use commodity derivatives, 20 that explicitly state that they do not use commodity derivatives, and 39 that don't mention any use of derivatives. Of the 172 firms that use commodity derivatives, Panel B shows that 146 explicitly state that they use derivatives only for hedging purposes, while 16 firms say they both hedge and speculate. For the remaining 10 firms, we cannot tell. In sum, $74 \%$ of the producers in the EDGAR sample state that they use commodity derivatives, while a maximum of $26 \%$ of the firms do not use commodity derivatives. Of the firms that use derivatives, $85 \%$ are, by their own admission, pure hedgers.

Panel $\mathrm{C}$ of Table 1 shows the instruments the firms use and their relative proportions. Forwards and futures are used in $29 \%$ of the firms, while swaps are used by $52 \%$ of the firms. Options and strategies, such as put and call spreads and collars, are used by $20 \%$ and $33 \%$ of the firms, respectively. Most options positions are not strong volatility bets. In particular, low-cost collars that are long out-of-the-money put and short out-of-the-money calls are the most common option strategy for producers - a position that is very similar to a short futures position. Thus, derivative hedging strategies that are linear, or close to linear, in the underlying are by far the most common.

We focus on short-term commodity futures - the most liquid derivative instruments in the commodity markets - in our empirical analysis. However, a considerable fraction of the hedging

\footnotetext{
${ }^{13}$ Another notable study of firm-level hedging behavior in commodities is Tufano (1996), who relies on proprietary data from gold mining firms.

${ }^{14}$ Since the introduction of Financial Accounting Standards Board's 133 regulation (Accounting for Derivative Instruments and Hedging Activities), effective for fiscal years beginning after June 15, 2000, firms are required to measure all financial assets and liabilities on company balance sheets at fair value. In particular, hedging and derivative activities are usually disclosed in two places. Risk exposures and the accounting policy relating to the use of derivatives are included in "Market Risk Information." Any unusual impact on earnings resulting from accounting for derivatives should be explained in the "Results of Operations." Additionally, a further discussion of risk management activity is provided in a footnote disclosure titled "Risk Management Activities \& Derivative Financial Instruments." Some firms, however, provided some information on derivative positions also before this date.
} 
is done with swaps, which are provided by banks over-the-counter, and often are longer term. On the one hand, this indicates that a significant proportion of producer's hedging is done outside the futures markets that we consider. On the other hand, banks in turn hedge their aggregate net exposure in the underlying futures market and in the most liquid contracts. For instance, it is common to hedge long-term exposure by rolling over short-term contracts (e.g., Metallgesellschaft). A similar argument can be made for the net commodity option imbalance held by banks in the aggregate. Therefore, producers' aggregate net hedging pressure is likely to be reflected in trades in the underlying short-term futures market.

\subsection{The Time-Series Behavior of Producer Hedging}

Information about hedging positions from accounting statements could potentially be used directly to assess the impact of time-varying producer hedging demand on commodity returns. However, there are significant data limitations for such use. First, FAS 133 requires the firms to report markto-market values of derivative positions, which are not directly informative about underlying price exposure. There is no agreed upon reporting standard or requirement for providing information on effective price exposure for each firm's derivative positions, which leads to either non-reporting, or very different reporting of such information. For instance, firms sometimes report notional outstanding or number of barrels underlying a contract, but not the direction of the position or the actual derivative instruments and contracts used, the 5\%-, 10\%-, or 20\%-delta with respect to the underlying, or Value-at-Risk measures (again sometimes without mention of direction of hedge). We went through all the quarterly and annual reports available for the firms with SIC codes 2910 and 2911 (50 firms) in the EDGAR database to attempt to extract (a) whether the firms were long or short the underlying, and (b) the extent of exposure in each quarter or year as measured by sensitivity to price changes in the underlying commodity futures price (i.e., a measure of Delta).

Panel D in Table 1 reports that of the 34 firms with these SIC codes that we could find in EDGAR, only 19 (56\%) gave information about the direction of the hedge (long or short the underlying). Of these, $80 \%$, on average, of the firm-date observations were short the underlying commodity. Since commodity producers are naturally long the commodity, one would expect that the producers' derivative hedge positions are always short the underlying. However, there are complicating factors. First, some firms do take speculative positions. Second, there are cases where hedging demand could manifest itself in long positions in the futures market. For instance, a pure refiner may have an incentive to go long crude oil futures to hedge its input costs, but short, say gasoline futures to hedge its production. This suggests that it might be fruitful to separate producers and producer refiners (such as Marathon Oil) from pure refiners (such as Frontier Oil) in the analysis, and we do so as a robustness check.

Of the 19 firms that reported whether they were long or short in the futures markets, we could only extract a reliable, and relatively long, time-series of derivative position exposure to the under- 
lying commodity price for 4 firms: Marathon Oil, Hess Corporation, Valero Energy Corporation, and Frontier Oil Corporation. Consequently, the data is not rich enough to provide a measure of aggregate producer hedging positions based on direct (self-reported) observations of producers' futures hedging demand, even for the relatively short period for which EDGAR data is available. Nevertheless, we show the relationship between the time series of hedging behavior and default risk for the 4 firms for which we were able to extract this information. This represents an interesting insight into the time-series variation in hedging, which complements existing analyses (such as Haushalter $(2000,2001))$ of the cross-sectional relation between hedging behavior and default risk measures.

\subsection{Observed Hedging Demand and Default Risk}

From the quarterly and annual reports of these four firms, we extract a measure of each firm's $\$ 1$ delta exposure to the price of crude oil (i.e., how does the value of the company's derivative position change if the price of the underlying increases by $\$ 1$ ). This measure of each firm's hedging position is constructed from, for instance, value-at-risk numbers that are provided in the reports by assuming log-normal price movements and using the historical mean and volatility from the respective commodity futures returns. In other cases, firms report delta's based on $5 \%, 10 \%$ and $20 \%$ moves in the underlying price, which are then used to construct the $\$ 1$ delta number as a measure of hedging demand.

We next compare the time-series of each of the firms' commodity derivatives hedging demand to each firm's Zmijewski-score and 3-year lagged stock return throughout the EDGAR sample. There are too few observations per firm to compare with the naive-EDF scores, which is only provided to us until the end of 2003. Figure $3 a$ shows the negative of the imputed delta and the Zmijewski-score for each of the four companies. Both variables are normalized to have mean zero and unit variance. The figure shows that there is a strong, positive correlation between the level of default risk, as measured by the Zmijewski-score and the amount of short exposure to crude oil using derivative positions for Marathon Oil, Hess Corp., and Valero Energy Corp. For Frontier Oil Corp., the hedging activity is strongly negatively correlated with the Zmijewski-score. The same pattern can be seen in Figure 3b, where each firm's hedging activity is plotted against the negative of its 3-year average stock returns. Marathon Oil and Hess both extract and refine oil and so it is natural that as default risk and hedging demand increases, these firms increase their short crude oil positions. Valero, however, is a pure refining company that one might argue should go more long crude oil as default risk increases. This does not happen, however, because Valero in fact holds inventory of its input, crude oil, as well as for refined products. This was inferred by reading Valero's quarterly reports, and is anecdotally quite a common happenstance for refiners. Thus, an increase in the demand for hedging leads to increasing hedge of both the input and output good inventories. Frontier Oil, however, behaves more as one might naively expect of a refiner, as the 
company does not hold significant crude inventory in this sample, and decreases its short crude positions as default risk increases. Finally, as a check that the proxies used capture default risk in our sample, Figure $3 c$ shows the time-series relation between Valero's 5-year CDS spread (obtained from Markit) and its short crude oil hedging. Valero is the only of these firms where CDS data was available to us. Again, we see a strong relation between hedging and default risk.

In sum, in these four firms, which constituted the best sample available in EDGAR of the producer firms, it is clear that hedging activity is time-varying, and related to the proposed proxies for fundamental hedging demand. However, the graphs highlight that one must take care when inferring expected hedging activity from whether a firm is involved only with extraction, extraction and refining, or purely refining. Essentially, all firms are to some extent naturally long crude oil, but for pure refiners, this is likely less true than for companies that engage in both extraction as well as refining - echoing the analysis in Ederington and Lee (2002).

We now turn to our analysis of the aggregate relationships between our proxies for fundamental hedging demand, spot returns and futures risk premia in the oil and gas markets. We will, however, use the non-hedging firms identified in the micro-analysis in this section and the separation between producers and refiners to perform robustness checks for our aggregate results to come.

\section{$5 \quad$ Aggregate Empirical Analysis}

In this section, we employ the aggregate measures of producer hedging demand, for which we reported summary statistics in the Data section, to test the empirical predictions of the model documented in Section 2.

\subsection{Commodity Futures and Spot Prices}

Our commodity futures price data is for NYMEX contracts and is obtained from Datastream. The longest futures return sample period available in Datastream goes from the first quarter of 1980 until the fourth quarter of 2006 (108 quarters; crude oil).

To create the basis and returns measures, we follow the methodology of Gorton, Hayashi and Rouwenhorst (2007). We construct rolling commodity futures excess returns at the end of each month as the one-period price difference in the nearest to maturity contract that would not expire during the next month. That is, the excess return from the end of month $t$ to the next is calculated as:

$$
\frac{F_{t+1, T}-F_{t, T}}{F_{t, T}}
$$

where $F_{t, T}$ is the futures price at the end of month $t$ on the nearest contract whose expiration date $T$ is after the end of month $t+1$, and $F_{t+1, T}$ is the price of the same contract at the end of month $t+1$. The quarterly return is constructed as the product of the three monthly gross returns in the 
quarter.

The futures basis is calculated for each commodity as $(F 1 / F 2-1)$, where $F 1$ is the nearest futures contract and $F 2$ is the next nearest futures contract. Summary statistics about these quarterly measures are presented in Table 2. Note that the means and medians of the basis in the table are computed using the raw data, while the standard deviation and first-order autocorrelation coefficient are computed using the deseasonalized basis, where the deseasonalized basis is simply the residual from a regression of the actual basis on four quarterly dummies. The basis is persistent across all commodities once seasonality has been accounted for.

Table 2 further shows that the excess returns are on average positive for all three commodities, ranging from $2.5 \%$ to $6.7 \%$, with relatively large standard deviations (overall in excess of $20 \%$ ). As expected, the sample autocorrelations of excess returns on the futures are close to zero. The spot returns are defined using the nearest-to-expiration futures contract, again consistent with Gorton, Hayashi and Rouwenhorst (2007):

$$
\frac{F_{t+1, t+2}-F_{t, t+1}}{F_{t, t+1}} .
$$

Again, the quarterly return is constructed by aggregating monthly returns as defined above. Note that the spot returns display negative autocorrelation, consistent with mean-reversion in the level of the spot price.

\subsection{Inventory}

For all four energy commodities, aggregate U.S. inventories are obtained from the Department of Energy's Monthly Energy Review. For Crude Oil, we use the item: "U.S. crude oil ending stocks non-SPR, thousands of barrels." For Heating Oil, we use the item: "U.S. total distillate stocks". For Gasoline, we use: "U.S. total motor gasoline ending stocks, thousands of barrels." Finally, for Natural Gas, we use: "U.S. total natural gas in underground storage (working gas), millions of cubic feet." Following Gorton, Hayashi and Rouwenhorst (2007), we compute a measure of the discretionary level of aggregate inventory by subtracting a moving trend of inventory from the quarterly realized inventory (so as to avoid look-ahead bias). Quarterly trend inventory is created using a Hodrick-Prescott filter with the recommended smoothing parameter (1600). In all specifications that employ inventories, we also include quarterly dummy variables, to control for the strong seasonality present in inventories. Table 2 shows summary statistics of the resulting aggregate inventory measure, i.e., the cyclical component of inventory stocks, for the commodities. Once the seasonality in inventories is accounted for, the trend deviations in inventory are persistent. 


\subsection{Hedger Positions Data.}

The Commodity Futures Trading Commission (CFTC) reports aggregate data on net "hedger" positions in a variety of commodity futures contracts. These data have been used in several papers that arrive at differing conclusions about their usefulness. For example, Gorton, Hayashi and Rouwenhorst (2007) find that this measure of hedger demand does not significantly forecast forward risk premiums, while De Roon, Nijman and Veld (2000) find that they hold some forecasting power for futures risk premia. The CFTC hedging classification has significant shortcomings; in particular, anyone that can reasonably argue that they have a cash position in the underlying can obtain a hedger classification. This includes consumers of the commodity, and more prominently, banks that have offsetting positions in the commodity (perhaps on account of holding a position in the swap market). The line between a hedge trade and a speculative trade, as defined by this measure, is therefore blurred. We note these issues with the measure as they may help explain why the forecasting power of hedging pressure for futures risk premia is debatable, while our measures of default risk do seem to explain futures risk premia. Nevertheless, we use the CFTC data as a check that our measures of producers' hedging demand is in fact reflected in futures positions as noted by the CFTC.

The Hedger Net Positions data are obtained from Pinnacle Inc., which sources data directly from the Commodity Futures Trading Commission (CFTC). Classification into Hedgers, Speculators and Small traders is done by the CFTC, and the reported data are the total open positions, both short and long, of each of these trader types across all maturities of futures contracts. We measure the net position of all hedgers in each period as:

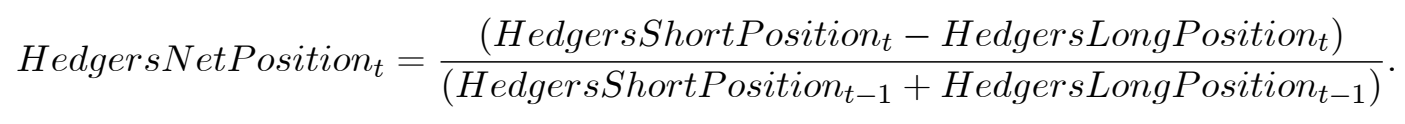

This normalization means that the net positions are measured relative to the aggregate open interest of hedgers in the previous quarter. Summary statistics on these data are shown in Table 2. First, the hedger positions are on average positive, which means investors classified as "hedgers" are on average short the commodity forwards. However, the standard deviations are relatively large, indicating that there are times when the CFTC classified "hedgers" are actually net long commodity futures contracts.

\subsection{Aggregate Controls}

In our empirical tests, we use controls to account for sources of risk premia that are not due to hedging pressure. In a standard asset pricing setting, time-varying aggregate risk aversion and/or aggregate risk can give rise to time-variation in excess returns. This is reflected in the pricing kernel, $\Lambda$, of equity-holders in the model. To capture this source of variation, therefore, we include 
business cycle variables that have been shown to forecast excess asset returns in previous research.

We include the Default Spread: the difference between the Baa and Aaa rated corporate bond yields, which proxies for aggregate default risk in the economy and has been shown to forecast excess returns on stocks and bonds (see, e.g., Fama and French (1989), and Jagannathan and Wang (1996)). Following Harrison and Yogo (2009), we also include the Term Spread, constructed as the difference between the yield on a 5-year zero-coupon T-bond and the yield on the 3-month T-bill. We do not include the aggregate dividend yield, as this variable has no forecasting power for commodity returns (results available on request). Finally, to account for time-varying expected commodity spot demand, we use a forecast of quarterly GDP growth, obtained from the Philadelphia Fed's survey of professional forecasters.

\subsection{Commodity Specific Controls}

We also include controls that are specific to each commodity. As emphasized in Gorton, Hayashi, and Rouwenhorst (2008), the cyclical level of inventory is related to the conditional volatility of the commodity price, and as such, the volatility of spot and futures returns. The basis is related to (the probability) of an inventory stock-out, and so is expected to have predictive power mainly for the spot return. When there is ample inventory, however, the basis is not expected to be informative about spot or futures returns, and so it should not drive out predictability that arises from producer hedging demand. The lagged futures return is included to capture autocorrelation in excess futures returns not captured by the other controls. A component of the measures of producer default risk will be related to lagged commodity returns (as firm performance is related to commodity returns), and we want to ensure that the proxies for producer hedging demand are not simply capturing this autocorrelation in commodity returns. Finally, we include quarterly dummy variables in all the regressions as both the independent and many of the dependent variables in the regressions exhibit seasonalities.

\subsection{Empirical Results}

Before we test the predictions of the model with respect to the expected commodity futures and spot return, we first perform an additional check of the validity of the aggregate measures of producers' fundamental hedging demand by relating them to the CFTC measures of aggregate net hedging demand. As previously explained, the aggregate CFTC data on hedger positions is noisy. However, a noisy measure of hedger positions should still contain information about the underlying true producer hedging demand. 


\subsubsection{CFTC Hedging Positions and Producer Hedging Demand}

We construct the hedger net position variables from the CFTC data as the net short position, so we should expect a positive relation between the default risk and CFTC hedger positions. Table 3 reports the results of the regression:

$$
\text { HedgerNetPos }{ }_{i, t}=\beta_{i} \text { DefRisk }_{i, t}+\text { ControlVariables }{ }_{t}+u_{i, t},
$$

where $i$ denotes the relevant commodity (crude oil, heating oil, gasoline, or natural gas). The term "ControlVariables" is a catch-all term for the inclusion of the control variables described earlier, and "DefRisk" denotes the average producer Zmijewski-score, the average producer Naive $\mathrm{EDF}$, or the negative of the 3-year average producer stock returns (so as to make the expected regression coefficient, $\beta_{i}$, positive in all specifications). In these regressions, both the left- and right-hand side variables are normalized to have unit variance, so the regression coefficients can be easily interpreted. Table 3 shows that 10 out of 12 of the regression coefficients $\left(\beta^{\prime} s\right)$ are positive and that half are positive and significant at the $10 \%$ level or greater at the individual commodity level. The significance level is overall increasing in the number of observations available (Natural Gas and Gasoline have the fewest observations and largely insignificant coefficients). To alleviate issues regarding power, we present in the right-most column of Table 3 the $\beta$-coefficients from pooled regressions across all commodities for all the default risk measures. In all three cases, the regression coefficient is positive and significant at the $5 \%$ level. ${ }^{15}$ Thus, the aggregate measures of producer hedging demand are indeed significantly and positively related to the CFTC recorded aggregate "hedger" positions.

\subsubsection{Commodity Futures Returns}

Next, we evaluate the first part of Proposition 1, namely that increases in fundamental hedging demand are associated with higher futures risk premia. To do so, we run a standard forecasting regression for excess commodity futures return, using our default risk proxy for fundamental hedging demand. In particular, we regress quarterly (excess) futures returns on one quarter lagged measures of default risk and control variables:

$$
\text { ExcessReturns }_{i, t+1}=\beta_{i} \text { DefRisk }_{i, t}+\text { ControlVariables }_{t}+u_{i, t+1}
$$

where $i$ denotes the commodity and $t$ denotes time measured in quarters.

Table 4 shows the results of the above regression across the four commodities considered, as

\footnotetext{
${ }^{15}$ Note that in all individual-commodity regressions in this paper, standard errors are constructed using the NeweyWest (1987) method, which is robust to heteroskedasticity and autocorrelation of the error terms, and in all pooled regressions, we employ Rogers $(1983,1993)$ errors that are robust to heteroskedasticity, own and cross-autocorrelation and contemporaneous correlation across all commodities in each quarter.
} 
well as a pooled regression across all commodities. First, we note that in all cases, the regression coefficients have the predicted sign: an increase in default risk forecasts higher futures returns over the next quarter. For ease of interpretation, the default risk measures are in all cases normalized to have unit variance, and thus the regression coefficients give the expected futures return response to a one standard deviation change in the aggregate default risk measure. The average expected return response is highly economically significant at $4 \%$ per quarter across the commodities. The standard deviation of quarterly futures returns of Crude Oil, Heating Oil, and Gasoline is 20\% per quarter, and so the implied quarterly $R^{2}$ from the effect of the producer fundamental hedging demand alone is $4 \%$ for these commodities. This is high for a quarterly forecasting regression, considering the high persistence of the predictive default risk variables. ${ }^{16}$

The pooled regressions show that the effect of producer hedging demand is significant at the $5 \%$ level or greater for all the default measures. In the individual regressions, the evidence is strongest for Crude Oil, Heating Oil and Gasoline, and somewhat weaker for Natural Gas. However, the the latter has the shortest time-series (49 and 63 quarters when using the naive EDF or the two other default risk measures, respectively), which potentially explains the lower significance. Furthermore, Haushalter $(2000,2001)$ points out that hedging for Natural Gas producers in particular is less prevalent and more risky since there is substantial basis risk depending on the location of the producer relative to the location at which the benchmark price is set. ${ }^{17}$ This may also be responsible for the somewhat weaker results we see for this commodity throughout the paper.

In sum, we conclude that there is strong evidence that commodity producers' fundamental hedging demand is positively related to the expected return of commodity futures, consistent with the model in Section 2. Next, we report three robustness checks of our results.

Volatility Interaction. From the expression for the futures risk premium in Equation (11), the model implies an interaction between fundamental hedging demand $\left(\gamma_{p}\right)$ and the commodity futures return volatility. In particular, a change in fundamental hedging demand has a larger impact on the futures risk premium if volatility is high. We test this relation by running the regression:

ExcessReturns $_{i, t+1}=\beta_{i, 1} R V_{i, t}+\beta_{i, 2}$ DefRisk $_{i, t}+\beta_{i, 3} R V_{i, t} \times$ DefRisk $_{i, t}+$ ControlVariables $_{t}+u_{i, t+1}$,

where $i$ denotes the commodity, $t$ denotes time measured in quarters, and $R V_{i, t}$ is a measure of the conditional variance at time $t$ of futures returns from time $t$ to $t+1$ for commodity $i$ (the realized variance). The model predicts a positive coefficient on the interaction term $\left(\beta_{i, 3}\right)$. Since volatility

\footnotetext{
${ }^{16}$ The default risk measures are also significant predictors of futures returns in simple univariate regressions (not reported).

${ }^{17} \mathrm{He}$ mentions, for example, that in 1993 the correlation between the prices of natural gas sold at Wheeling Ridge Hub in California and gas sold at Henry Hub in Louisiana (the benchmark for prices on NYMEX contracts) was slightly less than $30 \%$
} 
also appears in the covariance term in Equation (11), it is important to include its direct effect. Further, the conditional volatility of futures returns is an indirect control for supply uncertainty (probability of inventory stock-out or other production shocks) that may be correlated with default risk. The estimate of the conditional variance we use is the realized average squared daily futures returns from time $t$ to $t+1$. The use of the realized variance as the volatility measure is convenient as there are both seasonalities and trends in volatility over the sample. Table 5 shows the results of the above regression, where all the independent variables are normalized to have zero mean and unit variance. Focusing on the pooled regression results in the rightmost column, we see that including the volatility interaction term increases the average response $\left(\beta_{2}\right)$ from its level in Table 4 , from $4 \%$ to about $6 \%$. The effect is significant for all the default risk measures and the signs are as predicted by the model.

Producers versus refiners. Next, we consider the forecasting power of the default risk measures based on all firms in our sample, as before, versus the subset of firms that state they are solely refiners. To separate these two groups, we peruse the accounting statements from EDGAR to find firms that are solely refiners. As discussed in Section 3, pure play refiners may hedge short crude oil if they store crude, but if they do not they have an incentive to hedge by going long as they use crude oil as an input good. Thus, aggregate default risk measures based only on pure play refiners' data should forecast futures returns with a negative sign (per the results for Frontier Oil discussed in Section 3), when combined with the default risk measures that we have been using that are derived from all firms in the sample. In particular, we run the regression:

$$
\text { ExcessCrude }_{t+1}=\beta_{1} \text { DefRisk_All } l_{t}+\beta_{2} \text { DefRisk_Refiner } s_{t}+\text { ControlVariables }{ }_{t}+u_{t+1},
$$

where DefRisk_All are the aggregate default risk measures used before, and DefRisk_Refiners are the default risk measures constructed using only firms that are identified as pure play refiners. The independent variable (ExcessCrude) is the one-period-ahead return on crude oil futures. Table 6 shows that all the default risk measures based on pure play refiners come in negative, as conjectured, and significant for the Zmijewski-score and lagged negative 3-year stock returns. The Table also shows the corresponding forecasting regression for changes in the spot price, which yield similar results.

Hedgers versus Non-Hedgers. Next, we consider the forecasting power of default risk measures based on producers that state they are hedgers, and contrast these measures with measures derived from producers that are stated non-hedgers. First, we use the CFTC measures to substantiate a split of the sample of producing firms into firms that state they hedge, versus firms that are self-stated non-hedgers. This split is then used as a robustness check for the futures return 
forecasting regressions. The goal is to substantiate that our results arise from fundamental hedging demand rather than from any omitted variable in our empirical model that simultaneously drives defaults and the commodity futures risk premium.

We split the producers into two groups based on whether a producer is a stated hedger or non-hedger, according to the data we gathered in Section 3 on individual firms' disclosures about their hedging policies. If our model is correct, the forecasting power of default risk for futures risk premia should arise only for those firms that engage in hedging. To implement the split, we must implicitly extrapolate the behavior of the sample firms backwards in time. This is because the EDGAR data only contains information back to 1998. Panel A of Table II identifies 20 firms as stated non-hedgers and 146 firms as stated hedgers. We construct aggregate Zmijewski-scores, Naive EDF's, and 3-year average returns based on these two sets of firms.

One concern that arises in this context is that hedging firms tend to be quite a bit larger than the non-hedgers. In particular, the average market value of the hedgers is $\$ 3,035$ million versus only $\$ 313$ million for stated non-hedgers. Furthermore, the sample of hedging firms is larger, which reduces the idiosyncratic noise in aggregate measures constructed for this group of firms. To facilitate comparisons that are not driven by these differences, we identify a matched sample of selfdescribed hedging producer firms, by removing the firms with the largest market values until the average market value of the small hedgers is about the same as for the non-hedgers ( $\$ 373$ million); the standard deviation of the market values is also then comparable to that of the non-hedgers. There are 59 firms in this matched sample, and we run our tests also using this matched sample.

To decrease the amount of noise in the proxy for fundamental hedging demand in these tests, we here define a consolidated default risk variable as simply an equal weighted average of the Zmijewskiscore, the naive EDF and the negative of the 3-year lagged stock return, where each of these variables have been normalized to have zero mean and unit variance. The resulting consolidated, aggregate default risk measures is also normalized to have unit variance so the regression coefficients are easy to interpret and compare to the previous results. ${ }^{18}$ Panel A of Table 7 shows the results of regressions pooled across commodities, with aggregate default risk measures based on hedger- as well as non-hedger firms on the right-hand-side:

$$
\begin{aligned}
\text { HedgerNetPos } & =\beta_{1}\left(\text { DefRisk_Hedger } s_{t}+\text { DefRisk_NonHedger } s_{t}\right) \ldots \\
& +\beta_{2} \text { DefRisk_NonHedger } s_{t}+\text { ControlVariables } s_{t}+u_{t} .
\end{aligned}
$$

A significant $\beta_{2}<0$ in these regressions would indicate that the regression coefficient on the default risk measure of non-hedging producers is significantly smaller than the regression coefficient on the

\footnotetext{
${ }^{18}$ Since we only have data on the naive EDF until 2003Q3, the final observations up until $2006 \mathrm{Q} 4$ are based on the Zmijewski-score and the 3-year stock returns only. The aggregate measure is normalized to have unit variance first in the period up to 2003Q2 and then also in the period after 2003Q2, so as to avoid building in a structural break in the volatility of the series.
} 
default risk measure of hedging producers. Panel A of Table 7 shows that in all the regressions the sign of $\beta_{1}$ is strongly positive, while the sign of $\beta_{2}$ is negative (and in most cases significant). Inspecting the magnitude of the regression coefficients, the implied regression coefficient on the non-hedgers' default risk measure $\left(\beta_{1}+\beta_{2}\right)$ is, as expected, close to zero. Thus, it is the default risk of those producers that hedge exposure, not default risk in general, that drives aggregate hedging pressure as defined by the CFTC.

Panel B of Table 7 considers the futures return forecasting regressions using the same crosssectional split of the sample of firms. Again the regressions are pooled across commodities and using only the consolidated default risk measure described above:

$$
\begin{aligned}
\text { ExcessReturn }_{t+1} & =\beta_{1}\left(\text { DefRisk_Hedger } s_{t}+\text { DefRisk_NonHedger } s_{t}\right) \ldots \\
& +\beta_{2} \text { DefRisk_NonHedger } s_{t}+\text { ControlVariables } s_{t}+u_{t+1} .
\end{aligned}
$$

The table confirms that the difference in the forecasting power is statistically significant. The $\beta_{1}$-coefficients are positive and significant at the $1 \%$ level or greater, while the $\beta_{2}$-coefficients are negative and significant at the $5 \%$ level or greater. Yet again, the implied coefficient on non-hedger default risk is close to zero in these specifications, which indicates that it is the default risk of firms that actually do hedge that matters for the futures risk premium, rather than default risk per se. ${ }^{19}$

\subsection{Commodity Spot Returns}

The model predicts a strong common component in spot and futures returns arising from the producers' fundamental hedging demand. Table 8 shows forecasting regressions of quarterly spot returns on the baseline lagged default risk measures, analogous to the regressions in Table 4 for the case of the futures returns. In particular, the regression is:

$$
\text { SpotReturns }_{i, t+1}=\beta_{i} \text { DefRisk } k_{i, t}+\text { ControlVariables }_{t}+u_{i, t+1}
$$

where the control variables are the same as before. The spot return is as defined in Section 3, the change in the price of the nearest to maturity contract relative to its previous value. Table 8 shows that there is a clear positive relation between default risk and spot returns on commodities. In particular, all the default risk measures are significant at the $5 \%$ level or better in the pooled regressions. The regression coefficients are very close to those found in the futures returns forecasting regressions, as predicted by the model - the common component in the expected futures and spot

\footnotetext{
${ }^{19}$ This result also shows that our matching approach provides a useful alternative to the classification schemes normally employed in the literature, namely, the CFTC reported classification of futures market participants into hedgers and speculators (see De Roon et. al.(2000)). Our approach also offers an alternative to identification schemes based purely on the reported functions of commodity firms such as producer, refiner, marketer or distributor (see Ederington and Lee (2002) for evidence that such classifications are noisy measures of firms' actual hedging activities).
} 
returns are of a similar size. Unlike in the results for futures returns, however, the basis is highly significant in the pooled regressions. This is also consistent with the model, which predicts that the basis will indeed be more informative about future spot prices than futures risk premia.

Link between futures risk premium and the spot price. In the model, a decrease in the futures risk premium leads to an increase in the spot price as producers are willing to hold more inventory when the cost of hedging is lower. The spot regressions are consistent with this result, as ceterus paribus, an increase in the spot price leads to a lower expected spot return. To the extent that the massive increase in speculator demand for long commodity futures positions over the recent years led to a decrease in the futures risk premium, we should expect to have seen an increase in the spot price. This effect is due to the possibility for increased risk-sharing between producers and speculators on account of the lower futures risk premium. Note that an increase in spot prices can occur through this channel even if there are no other changes in the fundamentals (production and demand) of the commodity spot market.

\subsection{Speculator Activity}

Following Etula (2009) and Adrian and Shin (2009), we use the growth in intermediaries' (aggregate Broker-Dealer) assets relative to household asset growth as a measure of speculators' ease of access to capital in aggregate $\left(\gamma_{s}^{-1}\right)$. This data is constructed from the U.S. Flow of Funds data. Etula (2009) shows that high relative growth in Broker-Dealer asset predicts low subsequent commodity futures returns, consistent with a relaxation of capital constraints leading to a lower commodity futures risk premium. The Broker-Dealer data is available quarterly for the full sample period. In addition to this aggregate measure, we use the growth in Commodity Trading Advisors' (CTAs) aggregate assets-under-management (AUM) relative to aggregate household asset growth as a commodity specific measure of arbitrage capital. The CTA data is from a consolidated dataset, drawn from HFR, TASS and CISDM databases, and is available from 1994 until the end of the sample. ${ }^{20}$

Table 9 shows the results of forecasting regressions of the futures return, the spot return, and annual inventory (the inventory is annual to nullify the effect of seasonalities). In addition to the default risk measures used previously (the Zmijewski-score, the naive EDF and the 3-year stock return), we add either the Broker-Dealer or the CTA measure of arbitrage activity as an independent variable. The control variables used are the same as elsewhere in the paper. The table shows that the predictions of the model, listed in Proposition 1, are borne out in the data: expected spot and futures returns are (1) decreasing in speculator risk appetite, as proxied by speculator relative asset growth, (2) increasing in producer hedging demand, and (3) the signs are the opposite when

\footnotetext{
${ }^{20}$ The panel of dollar AUM data is winsorized at the 0.25 and 99.75 percentile points and then aggregated across all funds in specific self-declared strategies each quarter. These strategies are 'CPO-Multi Strategy', 'CTA - Commodities', 'CTA-Systematic/Trend-Following', 'Managed Futures' and 'Sector Energy'.
} 
inventory holdings are the dependent variable. All the signs are as predicted and only 3 out of 36 regression coefficients are statistically insignificant. The regression also shows that real quantities (in this case inventory) are affected by limits to arbitrage and hedging demand, as predicted by the model.

The interaction of speculator activity and producer hedging demand. In the discussion of Figure 1, which shows the predictions of the calibrated model, we noted that the model predicts an intuitive interaction between the severity of the speculator constraint and producers' fundamental hedging demand. In particular, if speculators have ample capital, they are willing to cheaply take the opposite side of producers' hedge-motivated futures demand, while if speculator capital is scarce, the compensation required (the futures risk premium) is large.

To empirically evaluate this interaction, we check whether the component of the Crude Oil futures risk premium that is due to hedging pressure is negatively correlated with speculator relative asset growth. The proxy for the fundamental hedging demand used here is the consolidated default risk measure, based on a weighted average of the three default risk measures. The proportion of the risk premium due to producer hedging demand is constructed using the same regressions as in Table 4 and Equation (21). In particular, the estimated risk premium due to producer hedging demand $\left(\hat{\beta}_{\text {DefRisk }}\right.$ DefRisk $\left.k_{t}\right)$ is divided by the total estimated risk premium $\left(\hat{\beta}_{\text {All }}\right.$ AllControls $s_{t}+$ $\hat{\beta}_{\text {DefRisk }}$ DefRisk $k_{t}$, at each point in time. This measure is then squared to create a conditional $R^{2}$, and we take the log of this measure to reduce its skewness. While the regressions are quarterly, we sum to an annual, overlapping quarterly series to avoid seasonalities and to better capture the underlying lower frequency dynamics. The asset growth measures are also summed to an annual, overlapping quarterly series. To avoid any systematic component in either of the series, the measures of arbitrageur asset growth and default risk are orthogonalized with respect to the controls.

Figure 4 shows the time-series of the speculator activity and producer hedging component of the risk premium over the sample period. Both variables are normalized to have zero mean and unit variance for ease of comparison. The sample correlation and significance level is also shown in the Figure. For the full sample using the Broker-Dealer measure (the top plot) the correlation is -0.17 and significant at the $5 \%$ level. That is, the proportion of the commodity futures risk premium that is due to producer hedging demand tends to be low when arbitrage capital is high and high when arbitrage capital is low, as predicted by the model. The middle plot on Figure 4 shows that this relation is stronger in the last 12 years of the sample. Here the correlation is -0.42 and significant at the 1\% level. For the CTA data, which goes from 1994 to 2006, the full sample relation is insignificant, although slightly positive, while the relation is strongly negative (-0.36) and significant at the $5 \%$ level from 2000 until the end of the sample, when the flows of speculator capital to the commodity markets were particularly large and volatile. 
In sum, the evidence presented here indicates that time-varying market segmentation, due to time-variation in the severity of limits to arbitrage for speculators in the commodity market, impacts futures and spot commodity prices and inventories, through the hedging demand of producing firms. In particular, there is an intuitive, lower frequency interaction between speculator capital and the impact of producer hedging demand and market prices that is uncovered when we consider annual measures of hedging demand and speculator capital supply.

\subsubsection{Other Robustness Tests}

When splitting the sample, all the pooled regression coefficients indicate a positive relation between producer fundamental hedging demand and the futures risk premium in the first half of the sample. However, this effect is only statistically significant for the 3 year lagged return measure. The predictability evidence is stronger in the second half of the sample. Here all the pooled regressions are significant at the $1 \%$ level or better. The magnitude of the regression coefficients are, however, comparable across the samples. We also considered the following additional controls: Surprise OPEC production to control for international supply shocks, and aggregate Zmijewski-score of airlines - the latter as a measure of hedging demand of firms that are consumers of the commodity. None of these controls affect the economic or statistical significance of the reported results. ${ }^{21}$

\section{Conclusion}

We build a theoretical model in which the interaction between commodity producers who are averse to price fluctuations, and capital constrained speculators that invest in commodity markets determines commodity spot prices and commodity futures risk premia in equilibrium. Using a theoretically and empirically motivated proxy for the fundamental hedging demand of commodity producers - their default risk - and data from oil and gas markets, we find evidence to support the predictions of the model. Our main insight is that the hedging demand of producers is an important channel through which trading in commodity futures markets can affect spot prices. This occurs in our model because futures markets allow producers' inventory holdings to better adjust to current and future demand shocks.

Our model and results provide a useful lens through which to view an important debate about recent gyrations in commodity prices. Between 2003 and June 2008, energy, base metals, and precious metals experienced price rises in excess of $100 \%$. Over the same period, there was a huge increase in the amount of capital committed to long positions in commodity futures contracts. ${ }^{22}$

\footnotetext{
${ }^{21}$ These results are not reported, but they are available upon request.

${ }^{22}$ In July 2008, pension funds and other large institutions were reportedly holding over $\$ 250$ billion in commodity futures (mostly invested through indices such as the S\&P GSCI) compared to their $\$ 10$ billion holding in 2000 (Financial Times, July 8 2008)
} 
While these trends occurred concurrently, some market practitioners and economists vehemently argued that the speculative investments of financial players in the futures market have no direct relationship with commodity spot prices. Other commentators (most notably, Michael Masters, a hedge-fund manager, and George Soros, who both testified to the US Congress) have blamed speculative activity for recent commodity price rises. A third group (one that includes former Federal Reserve Chairman Alan Greenspan) has taken an intermediate view - that commodity spot prices are fundamentally driven by physical demand, but that financial speculation has played some role in recent price rises. This last set of commentators has also argued that financial speculation is in fact stabilizing, for some of the reasons we outline in the model: the long positions taken by financial investors have enabled producers to take short hedging positions and hold larger inventories, which increases current spot prices and should stabilize prices going forward.

In support of this last view, we agree with the chain of reasoning specified for the rise in spot prices. This is also consistent with the fallout of the sub-prime crisis in 2008, which increased speculator risk-aversion and simultaneously raised producer default risk. This increased producer hedging demand at the same time that it became costlier to hedge, causing inventories to eventually fall and lowering spot prices. We acknowledge that our theory, which is based on risk-sharing between producers and speculators, is unlikely to explain the full magnitude of the rise and fall in oil prices witnessed recently. Rather than a complete explanation, we view the mechanism we have outlined as a likely contributing factor to recent price movements.

\section{References}

[1] Acharya, Viral V., Yakov Amihud and Lubomir Litov (2007) Creditor Rights and Corporate Risk-taking, Working Paper, New York University Stern School of Business.

[2] Adrian, Tobias, and Hyun Song Shin (2009) Liquidity and Leverage, Journal of Financial Intermediation, forthcoming.

[3] Altman, Edward I. (1968), "Financial Ratios, Discriminant Analysis and the Prediction of Corporate Bankruptcy," Journal of Finance, Sep, 589-609.

[4] Amihud, Yakov and Baruch Lev (1981), "Risk reduction as a managerial motive for conglomerate mergers," Bell Journal of Economics, 12, 605-618.

[5] Anderson Ronald W. and Jean-Pierre Danthine (1980), "Hedging and Joint Production: Theory and Illustrations," Journal of Finance, Vol. 35, No. 2, pp. 487-498.

[6] Anderson Ronald W. and Jean-Pierre Danthine (1983), "Hedger Diversity in Futures Markets," The Economic Journal, Vol. 93, No. 370, pp. 370-389. 
[7] Baird, D.G. and Rasmussen, R.K. (2006), "The prime directive," Working Paper, University of Chicago.

[8] Berk, Jonathan and Richard Green, "Mutual Fund Flows and Performance in Rational Markets," Journal of Political Economy, December 2004, 112(6):1269-1295.

[9] Bessembinder, Hendrik (1992), "Systematic Risk, Hedging Pressure, and Risk Premiums in Futures Markets," Review of Financial Studies 5: 637-667.

[10] Bessembinder, Hendrik and Kalok Chan (1992), "Time Varying Risk Premia and Forecastable Returns in Futures Markets" Journal of Financial Economics, pp. 169-193.

[11] Bessembinder, H. and M. Lemmon (2002), "Equilibrium Pricing and Optimal Hedging in Electricity Forward Markets," Journal of Finance, 62(3), pp. 1347-1382.

[12] Bharath, Sreedhar and Tyler Shumway (2008), "Forecasting Default with the Merton Distanceto-Default Model" Review of Financial Studies 21 (3), pp. 1339-1369.

[13] Breeden, Douglas and S. Viswanathan (1990), "Why do firms hedge? An asymmetric information model", Working Paper, Fuqua School of Business, Duke University.

[14] Brennan, Michael (1958), "The Supply of Storage," American Economic Review 48: 50-72.

[15] Brennan, Michael (1991), "The Price of Convenience and the Valuation of Commodity Contingent Claims", in Diderik Lund, and Bernt Øksendal, eds.: Stochastic Models and Option Values (North-Holland, Amsterdam ).

[16] Carter, Colin A., Gordon C. Rausser and Andrew Schmitz (1983), "Efficient Asset Portfolios and the Theory of Normal Backwardation," Journal of Political Economy, 91(2), pp. 319-331.

[17] Cassasus, Jaime and Pierre Collin-Dufresne (2005), "Stochastic Convenience Yields Implied from Commodity Futures and Interest Rates", Journal of Finance, 60(5), pp. 2283-2332.

[18] Cassasus, Jaime, Pierre Collin-Dufresne, and Bryan Routledge (2008), “", Working Paper, Columbia University

[19] Chang, Eric C. (1985), "Returns to Speculators and the Theory of Normal Backwardation," Journal of Finance 40(1), pp. 193-208.

[20] Coughlan, Anne and Ronald Schmidt (1985) "Executive compensation, management turnover, and firm performance: An empirical investigation", Journal of Accounting and Economics, 7 , 43-66. 
[21] Danielsson, J., Shin, H.S and J. Zigrand. 2008. "Endogenous Risk and Risk Appetite." Working paper, London School of Economics and Princeton University.

[22] Deaton, Angus and Guy Laroque (1992), "On the Behavior of Commodity Prices," Review of Economic Studies 59: 1-23.

[23] Debreu, G. (1959). Theory of Value, New York: Wiley.

[24] DeMarzo, Peter and Darrell Duffie (1995), "Corporate incentives for hedging and hedge accounting", The Review of Financial Studies, 8(3), 743-771.

[25] De Roon, Frans, Theo Nijman, and Chris Veld (2000), "Hedging Pressure Effects in Futures Markets," Journal of Finance 55: 1437-1456.

[26] Ederington Louis and Jae-Ha Lee (2002), "Who Trades Futures and How: Evidence from the Heating Oil Futures Market," Journal of Business, 75(2), 353-373.

[27] Etula, Erkko (2009), "Risk Appetite and Commodity Returns," working paper, Harvard University.

[28] Fama, Eugene and Kenneth French (1987), "Commodity Futures Prices: Some Evidence on Forecast Power, Premiums, and the Theory of Storage," Journal of Business 60: 55-73.

[29] Fama, Eugene and Kenneth French (1989), "Business Conditions and Expected Returns on Stocks and Bonds", Journal of Financial Economics 25, 23 - 49.

[30] Fehle, Frank and Sergei Tsyplakov (2005), "Dynamic Risk Management: Theory and Evidence", Journal of Financial Economics 78(1), pp. 3-47

[31] Froot, Kenneth A. (1999), The Financing of Catastrophe Risk, University of Chicago Press.

[32] Froot, Kenneth A., David S. Scharfstein, and Jeremy C. Stein (1993), "Risk Management: Coordinating Corporate Investment and Financing Policies", Journal of Finance, 58(5), pp. 1629-1658.

[33] Gilson, Stuart C. (1989), "Management turnover and financial distress", Journal of Financial Economics, 25(2), 241-262.

[34] Gormley, Todd and David Matsa (2008), "Growing out of trouble? Legal liability and corporate responses to adversity," Working Paper, Northwestern University.

[35] Gorton, Gary, Fumio Hayashi, and K. Geert Rouwenhorst (2007), "The Fundamentals of Commodity Futures Returns," Yale ICF Working Paper No. 07-08. 
[36] Gromb, Denis and Dimitri Vayanos (2002), "Equilibrium and Welfare in Markets with Constrained Arbitrageurs" Journal of Financial Economics, 66, 361-407.

[37] Haushalter, G. David (2000), "Financing Policy, Basis Risk, and Corporate Hedging: Evidence from Oil and Gas Producers," Journal of Finance, 55(1), pp. 107-152.

[38] Haushalter, G. David (2001), "Why Hedge? Some Evidence from Oil and Gas Producers," Journal of Applied Corporate Finance, 13(4), pp. 87-92.

[39] He, Zhiguo and Wei Xiong (2008), "Multi-market Delegated Asset Management", unpublished working paper, Princeton university.

[40] Holmstrom, Bengt (1979), "Moral Hazard and Observability," The Bell Journal of Economics, Vol. 10, No. 1, pp. 74-91.

[41] Hong, Harrison and Motohiro Yogo (2009), "Digging Into Commodities", Working Paper, Princeton University.

[42] Hirshleifer, David (1988), "Residual Risk, Trading Costs, and Commodity Futures Risk Premia," Review of Financial Studies, 1(2), pp. 173-193

[43] Hirshleifer, David (1989), "Futures Trading, Storage and the Division of Risk: A Multiperiod Analysis," Economic Journal, 99(397), pp. 700-719.

[44] Hirshleifer, David (1990), "Hedging Pressure and Futures Price Movements in a General Equilibrium Model," Econometrica, 58(2), pp. 411-428.

[45] Jagannathan, Ravi (1985), "An Investigation of Commodity Futures Prices Using the Consumption-Based Intertemporal Capital Asset Pricing Model," Journal of Finance, vol. 40: $175-191$.

[46] Johnson, Timothy C. (2009), "Commodity Dependence and Aggregate Risk," Working paper, Universty of Illinois at Urbana-Champaign.

[47] Kaldor, Nicholas (1939), "Speculation and Economic Stability," Review of Economic Studies 7: 1-27.

[48] Keynes, John M. (1930), A Treatise on Money, vol. 2 (London: Macmillan).

[49] Litzenberger, R. and N. Rabinowitz (1995), "Backwardation in Oil Futures Markets: Theory and Empirical Evidence", Journal of Finance, 50(5), 1517-1545.

[50] Newey, Whitney and Kenneth West (1987), "A Simple, Positive Semi-Definite, Heteroskedasticity and Autocorrelation Consistent Covariance Matrix," Econometrica, 55(3), pp. 703-708 
[51] Ng, Victor and Stephen C. Pirrong (1994), "Fundamentals and Volatility: Storage, Spreads, and the Dynamics of Metals Prices," Journal of Business, vol. 67, no. 2 (April): 203-230.

[52] Ozelge, Sadi (2007), "The role of banks and private lenders in forced CEO turnover," Working Paper, New York University.

[53] Rogers, W. H. (1983), "Analyzing Complex Survey Data." Unpublished working paper, Rand Corporation, Santa Monica, CA.

[54] Rogers, W. H. (1993), "Regression Standard Errors in Clustered Samples." Stata Technical Bulletin Reprints STB-13:STB-18, pp. 88-94.

[55] Routledge, Bryan, Duane Seppi, and Chester Spatt (2000), "Equilibrium Forward Curves for Commodities," Journal of Finance 55: 1297-1338.

[56] Schwartz, Eduardo S. (1997), "The Stochastic Behavior of Commodity Prices: Implications for Valuation and Hedging", Journal of Finance 52, 923-973.

[57] Shleifer, Andrei, and Robert Vishny (1997), "The Limits of Arbitrage," Journal of Finance, 52(1), pp. 35-55.

[58] Smith, C., and Rene Stulz, 1985, "The determinants of firm's hedging policies", Journal of Financial and Quantitative Analysis 20, 391-405.

[59] Stulz, R., 1984, "Optimal hedging policies", Journal of Financial and Quantitative Analysis $19,127-140$.

[60] Tang, Ke and Wei Xiong (2009), "Index Investing and the Financialization of Commodities," Working paper, Princeton University.

[61] Tufano, Peter (1996), "Who Manages Risk? An Empirical Examination of Risk Management Practices in the Gold Mining Industry," Journal of Finance 51(4), 1097-1137.

[62] Warner, Jerold, Ross Watts, and Karen Wruck (1988), "Stock prices and top management changes", Journal of Financial Economics, 20, 461-492.

[63] Weisbach. Michael (1988) "Outside directors and CEO turnover", Journal of Financial Economics, 20, 431-460.

[64] Working, Holbrook (1949), "The Theory of the Price of Storage," American Economic Review 39: 1254-62.

[65] Zmijewski, Mark E. (1984), "Methodological Issues Related to the Estimation of Financial Distress Prediction Models," Journal of Accounting Research, Supplement, 59-82. 


\section{Table 1}

\section{Producer Hedging - Summary Statistics}

The data in this table is taken from 10-Q and 10-K filings in the Edgar database of firms with SIC codes 1310,1311 (mainly Natural Gas), and 2910 and 2911 (mainly Crude Oil and Refined Products). The Edgar files have only been obtained for firms that are verified to be crude oil or natural gas producers, oil refiners, and oil refined product marketers.

\section{Panel A:}

Firms in CompuStat sample (SIC 1310, 1311, 2910, 2911)

\begin{tabular}{rr} 
Number & Proportion \\
\hline 570 & \\
231 & \\
----79 & $17 \%$ \\
20 & $9 \%$ \\
172 & $74 \%$ \\
\hline
\end{tabular}

\section{Panel B:}

\section{Hedging vs. Speculation}

Firms that hedge

Firms that both speculate and hedge

Firms that do not specify

\section{Panel C:}

\begin{tabular}{rr} 
Number & Proportion \\
\hline 146 & $85 \%$ \\
16 & $9 \%$ \\
10 & $6 \%$ \\
\hline 172 & $100 \%$ \\
\hline
\end{tabular}

\section{Instruments}

Futures

Forwards

Options

Swaps*

Strategies**

Not Specified

\begin{tabular}{rr} 
Number & Proportion \\
\hline 47 & $20 \%$ \\
21 & $9 \%$ \\
48 & $20 \%$ \\
124 & $52 \%$ \\
80 & $33 \%$ \\
9 & $4 \%$
\end{tabular}

* Mainly of two types: Price Swaps and Spread Swaps

** Usually Collars, sometimes Put Spreads, Call Spreads

\section{Panel D:}

\begin{tabular}{|c|c|c|c|c|c|}
\hline $\begin{array}{l}\text { Commodity Class } \\
\text { and Direction (SIC } \\
\text { 2910, 2911) }\end{array}$ & $\begin{array}{r}\text { Firms in Edgar } \\
\text { where direction of } \\
\text { hedge is known }\end{array}$ & $\begin{array}{r}\text { Proportion of } \\
\text { all Edgar } \\
\text { firms }\end{array}$ & $\begin{array}{l}\text { \# of time- } \\
\text { series obs. }\end{array}$ & $\begin{array}{r}\text { \# of obs. where } \\
\text { firm is short }\end{array}$ & $\begin{array}{r}\text { Proportion of } \\
\text { all time-series } \\
\text { observations } \\
\end{array}$ \\
\hline Crude Oil* & 7 & $88 \%$ & 113 & 98 & $87 \%$ \\
\hline Natural Gas* & 3 & $50 \%$ & 42 & 32 & $76 \%$ \\
\hline Crude Oil + Natural & & & & & \\
\hline Gas** & 2 & $100 \%$ & 2 & 2 & $100 \%$ \\
\hline Refined Products*** & 4 & $44 \%$ & 50 & 41 & $82 \%$ \\
\hline Various $* * * *$ & 3 & $33 \%$ & 20 & 8 & $40 \%$ \\
\hline $\begin{array}{l}\text { All Commodity } \\
\text { classes }\end{array}$ & 19 & $56 \%$ & 227 & 181 & $80 \%$ \\
\hline
\end{tabular}

* Including positions reported as dominated by, but not exclusively comprising, this class

** Where reported as a combined class

*** Includes Gasoline, Diesel, Heating Oil, Jet Fuel and Asphalt

**** Where firms report all or some of the above classes together, sometimes combined with other classes such as electricity 
Table 2

\section{Summary Statistics}

This table reports summary statistics (mean, standard deviation, and the first autocorrelation coefficient AR(1)) of the variables AVGZm (cross-sectional average quarterly Zmijewski-score); AVG3Y (cross-sectional average of the timeseries average stock return per producer-firm over the past three years, each quarter); cross-sectional average naïve EDF (expected default frequency) from Bharath and Shumway (2008); basis (standard deviation and AR(1) computed for the deseasonalized series); spot returns; futures excess returns; net change in hedger's short positions and the change in aggregate inventory (standard deviation and AR(1) computed for the deseasonalized series), all measured quarterly as specified in the Data section. These statistics are computed for each of Crude Oil, Heating Oil, Gasoline and Natural Gas.

\begin{tabular}{llll}
\hline Crude Oil Heating Oil & Gasoline & Natural Gas \\
\hline
\end{tabular}

\section{AVGZm}

Mean

StdDev

AR(1)

\section{AVG3Y}

Mean

StdDev

AR(1)

Naïve EDF

Mean

StdDev

AR(1)

Basis

Mean

StdDev

AR(1)

Spot Return

Mean

StdDev

AR(1)

0.031

0.170

$-0.132$

Futures Excess Return

Mean

StdDev

AR(1)

Hedgers Net Position

Mean

StdDev

AR(1)

\section{Change in Inventory}

Mean

StdDev

AR(1)

0.009

0.010

0.930

0.037

0.030

0.018

0.462

0.043

$-0.123$

0.003

0.072

$-0.001$

0.044

$\begin{array}{llll}-2.689 & -2.727 & -2.692 & -2.587 \\ 0.318 & 0.323 & 0.329 & 0.417 \\ 0.951 & 0.939 & 0.969 & 0.702\end{array}$

0.009

0.009

0.004

0.010

0.010

0.013

0.953

0.923

0.040

0.036

0.099

0.032

0.029

0.073

0.743

0.719

0.829

0.026

0.040

$-0.039$

0.131

0.081

0.136

0.390

0.342

0.146

0.033

0.039

0.042

0.179

0.175

0.226

$-0.143$

$-0.137$

$-0.194$

0.044

0.067

0.025

0.210

0.298

$-0.078$

$-0.183$

0.035

0.080

0.069

0.067

0.114

0.099

0.068

$-0.010$

0.256

0.206

0.002

0.001

$-0.004$

0.088

0.035

0.156

0.506

0.138

0.415 
Table 3: CFTC Hedging Position vs Default Risk (Fundamental Hedging Demand)

The independent variables are CFTC aggregate net short hedger positions in Crude Oil, Heating Oil, Gasoline, and Natural Gas. The measures of fundamental hedging demand are the average Zmijewski-score (avgZm), the average Naive EDF (avgEDF), and the negative of the average returns the last 3 years (-avg3yr) for the sample of producers in each commodity. These dependent variables, as well as the independent variables, are normalized to have unit variance. The data is quarterly and contemporaneous. The controls are defined in the main text, and their regression coefficients are not reported for brevity. Heteroskedasticity and autocorrelation consistent standard errors (using 3 lags) are given in parentheses; *** means $p$-value $<0.01$, ** $p<0.05$, $* p<0.1$.

\begin{tabular}{cccccc}
\hline & $\begin{array}{c}\text { Crude } \\
\text { Uil }\end{array}$ & $\begin{array}{c}\text { Heating } \\
\text { Uil }\end{array}$ & Gasoline & $\begin{array}{c}\text { Natural } \\
\text { Gas }\end{array}$ & $\begin{array}{c}\text { Pooled } \\
\text { regression }\end{array}$ \\
\hline \hline avgZm & $0.188^{* *}$ & $0.273^{* * *}$ & -0.094 & 0.130 & $0.140^{* *}$ \\
& $(0.096)$ & $(0.075)$ & $(0.078)$ & $(0.085)$ & $(0.062)$ \\
$\mathrm{R}^{2}$ & $21.4 \%$ & $44.8 \%$ & $38.6 \%$ & $66.6 \%$ & $18.3 \%$ \\
$\#$ obs & 80 & 92 & 80 & 53 & 305 \\
& & & & & \\
avgEDF & $0.312^{* *}$ & $0.146^{*}$ & $0.173^{*}$ & 0.055 & $0.147^{* *}$ \\
& $(0.136)$ & $(0.086)$ & $(0.097)$ & $(0.068)$ & $(0.072)$ \\
$\mathrm{R}^{2}$ & $26.1 \%$ & $48.0 \%$ & $34.9 \%$ & $71.4 \%$ & $20.2 \%$ \\
$\#$ obs & 69 & 81 & 69 & 42 & 261 \\
& & & & & \\
-avg3yr & 0.101 & $0.204^{* * *}$ & -0.045 & 0.016 & $0.090^{* *}$ \\
& $(0.098)$ & $(0.059)$ & $(0.075)$ & $(0.061)$ & $(0.045)$ \\
$\mathrm{R}^{2}$ & $19.6 \%$ & $42.2 \%$ & $38.0 \%$ & $65.8 \%$ & $17.4 \%$ \\
\# obs & 80 & 92 & 80 & 53 & 305 \\
Controls? & yes & yes & yes & yes & yes \\
& & & & & \\
\hline \hline
\end{tabular}


Table 4: Forecasting Commodity Futures Returns

The independent variables are excess returns of futures on Crude Oil, Heating Oil, Gasoline, and Natural Gas. The measures of fundamental hedging demand are the average Zmijewski-score (avgZm), the average Naive EDF (avgEDF), and the negative of the average returns the last 3 years (-avg3yr) for the sample of producers in each commodity. These dependent variables are normalized to have unit variance. The data is quarterly and the dependent variables are lagged one quarter relative to the independent variables. The controls are defined in the main text of the paper, and their regression coefficients are reported here with the exception of the regression coefficients for the quarterly dummy variables. Heteroskedasticity and autocorrelation consistent standard errors (using 3 lags) are given in parentheses; $* * *$ means $p$-value $<0.01, * * p<0.05, * p<0.1$.

\begin{tabular}{|c|c|c|c|c|c|c|c|c|c|c|c|}
\hline \multicolumn{3}{|c|}{ Hedging Demand Measures } & \multicolumn{3}{|c|}{ Commodity Specific Variables } & \multicolumn{4}{|c|}{ Standard return predictors } & \multirow[b]{2}{*}{$\mathrm{N}$} & \multirow[b]{2}{*}{$\mathrm{R}^{2}$} \\
\hline avgZm & avgEDF & $-\operatorname{avg} 3 y r$ & Basis & Inventory & $\begin{array}{c}\text { Futures } \\
\text { Return }(-1)\end{array}$ & $\begin{array}{c}\Delta \text { GDP } \\
\text { forecast }\end{array}$ & $\begin{array}{c}\text { Term } \\
\text { Spread } \\
\end{array}$ & $\begin{array}{l}\text { Risk-free } \\
\text { rate }\end{array}$ & $\begin{array}{l}\text { Default } \\
\text { Spread } \\
\end{array}$ & & \\
\hline \multicolumn{12}{|c|}{ Panel A: Crude Oil } \\
\hline \multirow[t]{3}{*}{$\begin{array}{c}0.064 * * * \\
(0.022)\end{array}$} & & & $\begin{array}{l}-0.159 \\
(0.652)\end{array}$ & $\begin{array}{c}0.621 \\
(0.453)\end{array}$ & $\begin{array}{l}-0.067 \\
(0.078)\end{array}$ & $\begin{array}{c}0.036^{* *} \\
(0.014)\end{array}$ & $\begin{array}{c}-5.352 * * * \\
(1.796)\end{array}$ & $\begin{array}{l}-1.252 \\
(0.950)\end{array}$ & $\begin{array}{c}0.049 \\
(0.065)\end{array}$ & 90 & $17.3 \%$ \\
\hline & $\begin{array}{c}0.041^{* *} \\
(0.020)\end{array}$ & & $\begin{array}{c}0.092 \\
(0.657)\end{array}$ & $\begin{array}{c}1.026 \\
(0.648)\end{array}$ & $\begin{array}{l}-0.113 \\
(0.091)\end{array}$ & $\begin{array}{c}0.023 \\
(0.017)\end{array}$ & $\begin{array}{c}-4.544 * * \\
(2.272)\end{array}$ & $\begin{array}{c}-0.485 \\
(1.291)\end{array}$ & $\begin{array}{c}0.035 \\
(0.075)\end{array}$ & 76 & $17.9 \%$ \\
\hline & & $\begin{array}{c}0.061 * * * \\
(0.021)\end{array}$ & $\begin{array}{c}0.124 \\
(0.609)\end{array}$ & $\begin{array}{l}1.043 * * \\
(0.497)\end{array}$ & $\begin{array}{l}-0.090 \\
(0.084)\end{array}$ & $\begin{array}{c}0.033 * * \\
(0.015)\end{array}$ & $\begin{array}{c}-4.967 * * * \\
(1.839)\end{array}$ & $\begin{array}{c}-2.131 * * \\
(0.916)\end{array}$ & $\begin{array}{c}0.072 \\
(0.067)\end{array}$ & 90 & $16.8 \%$ \\
\hline \multicolumn{12}{|c|}{ Panel B: Heating Oil } \\
\hline \multirow[t]{3}{*}{$\begin{array}{c}0.047 * * \\
(0.019)\end{array}$} & & & $\begin{array}{c}0.015 \\
(0.183)\end{array}$ & $\begin{array}{l}-0.149 \\
(0.181)\end{array}$ & $\begin{array}{l}-0.106 \\
(0.071)\end{array}$ & $\begin{array}{l}0.015^{*} \\
(0.009)\end{array}$ & $\begin{array}{c}-2.793 * * \\
(1.341)\end{array}$ & $\begin{array}{l}-0.107 \\
(0.777)\end{array}$ & $\begin{array}{l}-0.006 \\
(0.044)\end{array}$ & 107 & $12.1 \%$ \\
\hline & $\begin{array}{c}0.040 * * * \\
(0.013)\end{array}$ & & $\begin{array}{c}0.073 \\
(0.177)\end{array}$ & $\begin{array}{l}-0.095 \\
(0.189)\end{array}$ & $\begin{array}{l}-0.116 \\
(0.078)\end{array}$ & $\begin{array}{c}0.011 \\
(0.008)\end{array}$ & $\begin{array}{c}-2.179^{*} \\
(1.275)\end{array}$ & $\begin{array}{c}0.150 \\
(0.750)\end{array}$ & $\begin{array}{c}0.059 \\
(0.045)\end{array}$ & 93 & $11.0 \%$ \\
\hline & & $\begin{array}{c}0.046^{* * *} \\
(0.016)\end{array}$ & $\begin{array}{c}0.046 \\
(0.157)\end{array}$ & $\begin{array}{l}-0.037 \\
(0.178)\end{array}$ & $\begin{array}{l}-0.103 \\
(0.072)\end{array}$ & $\begin{array}{c}0.015 \\
(0.010)\end{array}$ & $\begin{array}{c}-2.884 * * \\
(1.431)\end{array}$ & $\begin{array}{c}-0.513 \\
(0.792)\end{array}$ & $\begin{array}{l}-0.013 \\
(0.046)\end{array}$ & 107 & $12.2 \%$ \\
\hline \multicolumn{12}{|c|}{ Panel C: Gasoline } \\
\hline \multirow[t]{3}{*}{$\begin{array}{c}0.042 * * \\
(0.020)\end{array}$} & & & $\begin{array}{c}0.907 * * * \\
(0.151)\end{array}$ & $\begin{array}{c}0.238 \\
(0.545)\end{array}$ & $\begin{array}{c}-0.278 * * * \\
(0.057)\end{array}$ & $\begin{array}{c}0.050 * * * \\
(0.012)\end{array}$ & $\begin{array}{c}-4.793 * * * \\
(1.432)\end{array}$ & $\begin{array}{l}-0.924 \\
(1.150)\end{array}$ & $\begin{array}{c}0.112 * * \\
(0.058)\end{array}$ & 83 & $30.3 \%$ \\
\hline & $\begin{array}{c}0.066 * * * \\
(0.016)\end{array}$ & & $\begin{array}{c}0.785^{* * * *} \\
(0.146)\end{array}$ & $\begin{array}{l}-0.176 \\
(0.447)\end{array}$ & $\begin{array}{c}-0.294 * * * \\
(0.056)\end{array}$ & $\begin{array}{c}0.028 * * * \\
(0.010)\end{array}$ & $\begin{array}{l}-0.747 \\
(2.088)\end{array}$ & $\begin{array}{c}2.006 \\
(1.603)\end{array}$ & $\begin{array}{c}0.068 \\
(0.058)\end{array}$ & 69 & $35.8 \%$ \\
\hline & & $\begin{array}{c}0.045^{* *} \\
(0.020)\end{array}$ & $\begin{array}{c}0.897 * * * \\
(0.140)\end{array}$ & $\begin{array}{c}0.317 \\
(0.524)\end{array}$ & $\begin{array}{c}-0.284 * * * \\
(0.057)\end{array}$ & $\begin{array}{c}0.048^{* * *} * \\
(0.012)\end{array}$ & $\begin{array}{c}-4.633 * * * \\
(1.632)\end{array}$ & $\begin{array}{l}-1.325 \\
(1.127)\end{array}$ & $\begin{array}{c}0.134 * * \\
(0.060)\end{array}$ & 83 & $31.0 \%$ \\
\hline \multicolumn{12}{|c|}{ Panel D: Natural Gas } \\
\hline \multirow[t]{3}{*}{$\begin{array}{c}0.067 \\
(0.046)\end{array}$} & & & $\begin{array}{c}0.450 \\
(0.326)\end{array}$ & $\begin{array}{c}0.030 \\
(0.243)\end{array}$ & $\begin{array}{l}-0.094 \\
(0.160)\end{array}$ & $\begin{array}{c}0.057 \\
(0.041)\end{array}$ & $\begin{array}{l}-0.768 \\
(5.412)\end{array}$ & $\begin{array}{l}-0.579 \\
(2.732)\end{array}$ & $\begin{array}{c}0.135 \\
(0.155)\end{array}$ & 63 & $11.6 \%$ \\
\hline & $\begin{array}{c}0.016 \\
(0.039)\end{array}$ & & $\begin{array}{c}0.194 \\
(0.407)\end{array}$ & $\begin{array}{c}0.234 \\
(0.325)\end{array}$ & $\begin{array}{l}-0.050 \\
(0.198)\end{array}$ & $\begin{array}{l}0.093^{*} \\
(0.058)\end{array}$ & $\begin{array}{l}-7.829 \\
(7.235)\end{array}$ & $\begin{array}{l}-2.817 \\
(3.596)\end{array}$ & $\begin{array}{c}0.240 \\
(0.204)\end{array}$ & 49 & $13.6 \%$ \\
\hline & & $\begin{array}{c}0.108^{* *} \\
(0.045)\end{array}$ & $\begin{array}{c}0.330 \\
(0.340)\end{array}$ & $\begin{array}{c}0.271 \\
(0.292)\end{array}$ & $\begin{array}{l}-0.059 \\
(0.158)\end{array}$ & $\begin{array}{l}0.070^{*} \\
(0.041)\end{array}$ & $\begin{array}{l}-6.613 \\
(5.433)\end{array}$ & $\begin{array}{l}-3.077 \\
(2.808)\end{array}$ & $\begin{array}{c}0.067 \\
(0.140)\end{array}$ & 63 & $17.2 \%$ \\
\hline \multicolumn{12}{|c|}{ Panel E: Pooled Regression } \\
\hline \multirow[t]{3}{*}{$\begin{array}{c}0.038 * * \\
(0.016)\end{array}$} & & & $\begin{array}{c}0.117 \\
(0.106)\end{array}$ & $\begin{array}{c}0.117 \\
(0.106)\end{array}$ & $\begin{array}{c}0.038 \\
(0.070)\end{array}$ & $\begin{array}{c}0.029 * * \\
(0.011)\end{array}$ & $\begin{array}{c}-3.632 * * * \\
(1.327)\end{array}$ & $\begin{array}{l}-0.951 \\
(0.727)\end{array}$ & $\begin{array}{c}0.024 \\
(0.042)\end{array}$ & 343 & $11.4 \%$ \\
\hline & $\begin{array}{c}0.036^{* * *} \\
(0.009)\end{array}$ & & $\begin{array}{c}0.199 * * \\
(0.098)\end{array}$ & $\begin{array}{c}0.032 \\
(0.104)\end{array}$ & $\begin{array}{l}-0.109^{*} \\
(0.065)\end{array}$ & $\begin{array}{c}0.022 * * \\
(0.010)\end{array}$ & $\begin{array}{c}-3.157^{* *} \\
(1.608)\end{array}$ & $\begin{array}{l}-0.573 \\
(0.914)\end{array}$ & $\begin{array}{l}-0.009 \\
(0.049)\end{array}$ & 287 & $9.8 \%$ \\
\hline & & $\begin{array}{c}0.040 * * \\
(0.016)\end{array}$ & $\begin{array}{c}0.114 \\
(0.099)\end{array}$ & $\begin{array}{c}0.114 \\
(0.099)\end{array}$ & $\begin{array}{c}0.067 \\
(0.072)\end{array}$ & $\begin{array}{c}0.029 * * \\
(0.011)\end{array}$ & $\begin{array}{c}-4.186^{* * *} \\
(1.420)\end{array}$ & $\begin{array}{c}-1.515^{* *} \\
(0.765)\end{array}$ & $\begin{array}{c}0.036 \\
(0.046)\end{array}$ & 343 & $12.8 \%$ \\
\hline
\end{tabular}




\section{Table 5: Interaction of Conditional Variance and Fundamental Hedging Demand}

The independent variables are the quarterly futures return for Crude Oil, Heating Oil, Gasoline, and Natural Gas. The measures of fundamental hedging demand are the average Zmijewski-score (avgZm), the average Naive EDF (avgEDF), and the negative of the average returns the last 3 years (-avg3yr) for the sample of producers in each commodity. The measures of the conditional variance of each futures' returns is the realized variance (based on daily data). The dependent variables are normalized to have unit variance. The data is quarterly and the dependent variables are lagged one quarter relative to the independent variables. The controls are described in the main text in the paper. Heteroskedasticity and autocorrelation consistent standard errors (using 3 lags) are given in parentheses; *** means $p$-value $<0.01,{ }^{* *} p<0.05$, $* p<0.1$.

\begin{tabular}{|c|c|c|c|c|c|}
\hline & $\begin{array}{c}\text { Crude } \\
\text { Oil } \\
\end{array}$ & $\begin{array}{c}\text { Heating } \\
\text { Oil }\end{array}$ & Gasoline & $\begin{array}{c}\text { Natural } \\
\text { Gas }\end{array}$ & $\begin{array}{l}\text { Pooled } \\
\text { regression }\end{array}$ \\
\hline Realized Variance (RV) & $\begin{array}{l}-0.007 \\
(0.040)\end{array}$ & $\begin{array}{c}0.017 \\
(0.036)\end{array}$ & $\begin{array}{c}0.042 \\
(0.032)\end{array}$ & $\begin{array}{c}0.123^{* *} \\
(0.053)\end{array}$ & $\begin{array}{c}0.025 \\
(0.030)\end{array}$ \\
\hline avgZm & $\begin{array}{c}0.072 * * * \\
(0.023)\end{array}$ & $\begin{array}{c}0.048^{* *} \\
(0.019)\end{array}$ & $\begin{array}{c}0.053^{* * *} \\
(0.020)\end{array}$ & $\begin{array}{c}0.126^{* *} \\
(0.054)\end{array}$ & $\begin{array}{c}0.057 * * * \\
(0.019)\end{array}$ \\
\hline avgZm*RV & $\begin{array}{c}0.070 * * \\
(0.025)\end{array}$ & $\begin{array}{c}0.012 \\
(0.032)\end{array}$ & $\begin{array}{c}-0.006 \\
(0.025)\end{array}$ & $\begin{array}{c}0.158 * * * \\
(0.038)\end{array}$ & $\begin{array}{c}0.041 * \\
(0.022)\end{array}$ \\
\hline $\begin{array}{c}\mathrm{R}^{2} \\
\text { \# obs }\end{array}$ & $\begin{array}{c}19.8 \% \\
90\end{array}$ & $\begin{array}{c}12.7 \% \\
107\end{array}$ & $\begin{array}{c}33.1 \% \\
83\end{array}$ & $\begin{array}{c}28.1 \% \\
52\end{array}$ & $\begin{array}{c}13.3 \% \\
332\end{array}$ \\
\hline Realized Variance (RV) & $\begin{array}{c}0.039 \\
(0.041)\end{array}$ & $\begin{array}{c}0.043 \\
(0.030)\end{array}$ & $\begin{array}{c}0.029 \\
(0.026)\end{array}$ & $\begin{array}{c}0.102 * * \\
(0.046)\end{array}$ & $\begin{array}{c}0.054^{* * *} \\
(0.015)\end{array}$ \\
\hline naiveEDF & $\begin{array}{c}0.058^{* *} \\
(0.027)\end{array}$ & $\begin{array}{c}0.045^{* *} \\
(0.022)\end{array}$ & $\begin{array}{c}0.065^{* * *} \\
(0.023)\end{array}$ & $\begin{array}{c}0.184 * * * \\
(0.054)\end{array}$ & $\begin{array}{c}0.068^{* * *} \\
(0.012)\end{array}$ \\
\hline naiveEDF*RV & $\begin{array}{c}0.117^{* *} \\
(0.050)\end{array}$ & $\begin{array}{c}0.044 \\
(0.032)\end{array}$ & $\begin{array}{l}-0.047 \\
(0.033)\end{array}$ & $\begin{array}{c}0.132 * * * \\
(0.046)\end{array}$ & $\begin{array}{c}0.066^{* *} \\
(0.028)\end{array}$ \\
\hline $\begin{array}{c}\mathrm{R}^{2} \\
\text { \# obs }\end{array}$ & $\begin{array}{c}24.7 \% \\
76\end{array}$ & $\begin{array}{c}13.1 \% \\
93\end{array}$ & $\begin{array}{c}40.4 \% \\
69\end{array}$ & $\begin{array}{c}50.5 \% \\
38\end{array}$ & $\begin{array}{c}17.2 \% \\
276\end{array}$ \\
\hline Realized Variance (RV) & $\begin{array}{l}-0.049 \\
(0.036)\end{array}$ & $\begin{array}{c}0.009 \\
(0.031)\end{array}$ & $\begin{array}{c}0.044^{*} \\
(0.029)\end{array}$ & $\begin{array}{c}0.029 \\
(0.052)\end{array}$ & $\begin{array}{c}0.005 \\
(0.019)\end{array}$ \\
\hline -avg3yr & $\begin{array}{c}0.077^{* * *} \\
(0.025)\end{array}$ & $\begin{array}{c}0.046 * * * \\
(0.016)\end{array}$ & $\begin{array}{c}0.064^{* * *} \\
(0.019)\end{array}$ & $\begin{array}{l}0.082 * \\
(0.044)\end{array}$ & $\begin{array}{c}0.052^{* * *} \\
(0.014)\end{array}$ \\
\hline -avg3yr*RV & $\begin{array}{c}0.093^{* *} \\
(0.042)\end{array}$ & $\begin{array}{c}0.009 \\
(0.028)\end{array}$ & $\begin{array}{c}-0.059 * \\
(0.031)\end{array}$ & $\begin{array}{c}0.082^{* * *} \\
(0.020)\end{array}$ & $\begin{array}{c}0.034^{* * *} \\
(0.010)\end{array}$ \\
\hline $\mathrm{R}^{2}$ & $21.0 \%$ & $12.4 \%$ & $34.9 \%$ & $25.1 \%$ & $13.1 \%$ \\
\hline \# obs & 90 & 107 & 83 & 52 & 332 \\
\hline Controls? & yes & yes & yes & yes & yes \\
\hline
\end{tabular}




\section{Table 6: All firms versus Refiners: Spot and Futures forecasting regressions}

The independent variables are the quarterly futures return and percentage spot price change for Crude Oil, Heating Oil, Gasoline, and Natural Gas. The measures of fundamental hedging demand are the average Zmijewski-score (avgZm), the average Naive EDF (avgEDF), and the negative of the average returns the last 3 years (-avg3yr) for the sample of producers in each commodity. In addition to these measures based on all firms (All firms), we include these measures based on pure play refiners only (Refiners). The dependent variables are normalized to have unit variance. The data is quarterly and the dependent variables are lagged one quarter relative to the independent variables. The controls are described in the main text in the paper. Heteroskedasticity and autocorrelation consistent standard errors (using 3 lags) are given in parentheses; *** means $p$ value $<0.01,{ }^{* *} p<0.05, * p<0.1$.

\begin{tabular}{lccccccc}
\hline & \multicolumn{3}{c}{ Futures: Crude Oil } & \multicolumn{3}{c}{ Spot: CrudeOil } \\
& Zm-score & Naïve EDF & -avg3yr & Zm-score & Naïve EDF & -avg3yr \\
\hline \hline \multirow{2}{*}{ All firms } & $0.107^{* * *}$ & $0.055^{*}$ & $0.153^{* * *}$ & $0.090^{* * *}$ & $0.055^{*}$ & $0.136^{* * *}$ \\
& $(0.026)$ & $(0.033)$ & $(0.049)$ & $(0.024)$ & $(0.032)$ & $(0.049)$ \\
\multirow{2}{*}{ Refiners } & $-0.051^{* * *}$ & -0.006 & $-0.105^{*}$ & $-0.043^{* *}$ & -0.015 & $-0.093^{*}$ \\
& $(0.018)$ & $(0.024)$ & $(0.054)$ & $(0.017)$ & $(0.024)$ & $(0.052)$ \\
R2 & $18.8 \%$ & $19.0 \%$ & $19.1 \%$ & $25.6 \%$ & $27.2 \%$ & $26.5 \%$ \\
\# obs & 90 & 76 & 90 & 91 & 77 & 91 \\
& & & & & & & yes \\
Controls? & yes & yes & yes & & & & yes \\
& & & &
\end{tabular}




\section{Table 7 : Hedgers versus Non-Hedgers - pooled regressions}

The independent variables are the net short hedger positions as reported by the CFTC (Panel A) and excess returns of futures on Crude Oil, Heating Oil, Gasoline, and Natural Gas (Panel B). The regressions are pooled across the commodity classes. Further, the measure of fundamental hedging demand is, as explained in the main text, an average of the three measures used (average Zmijewski-score (avgZm), the average Naive EDF (avgEDF), and the negative of the average returns the last 3 years (-avg3yr)) for the sample of producers in each commodity. These dependent variables are calculated for both hedgers and non-hedgers. The hedger measure is calculated using all stated hedgers (regressions denoted (1)), as well as using a matched sample of small hedgers (regressions denoted (2)). The controls are explained in the main text. Heteroskedasticity and autocorrelation consistent standard errors (using 3 lags) are given in parentheses; *** means $p$-value $<0.01,{ }^{* *} p<0.05,{ }^{*} p<0.1$.

\begin{tabular}{lccccc}
\hline & $\mathrm{b}_{1}$ (Hedger + & $\mathrm{b}_{2}$ & & & \\
& Non-Hedger $)$ & (Non-Hedger) & Controls? & $\mathrm{R}^{2}$ & \# obs \\
\hline \hline
\end{tabular}

Panel A: Contemporaneous CTFC net short hedger positions as dependent variable

\begin{tabular}{|c|c|c|c|c|}
\hline $\begin{array}{c}\text { (1) Hedger measure constructed } \\
\text { using all hedgers }\end{array}$ & $\begin{array}{l}0.210 * * * \\
(0.050)\end{array}$ & $\begin{array}{l}-0.217 * * \\
(0.105)\end{array}$ & yes & $20.3 \%$ \\
\hline $\begin{array}{c}\text { (2) Hedger measure constructed } \\
\text { using small hedgers }\end{array}$ & $\begin{array}{c}0.175^{* * *} \\
(0.045)\end{array}$ & $\begin{array}{l}-0.124 \\
(0.114)\end{array}$ & yes & $19.4 \%$ \\
\hline
\end{tabular}

Panel B: Next quarter futures return as dependent variable

\begin{tabular}{|c|c|c|c|c|}
\hline $\begin{array}{c}\text { (1) Hedger measure constructed } \\
\text { using all hedgers }\end{array}$ & $\begin{array}{c}0.055^{* * *} \\
(0.016)\end{array}$ & $\begin{array}{c}-0.057 * * \\
(0.026)\end{array}$ & yes & $13.0 \%$ \\
\hline $\begin{array}{c}\text { (2) Hedger measure constructed } \\
\text { using small hedgers }\end{array}$ & $\begin{array}{c}0.054^{* * *} \\
(0.015)\end{array}$ & $\begin{array}{c}-0.045^{* *} \\
(0.019)\end{array}$ & yes & $12.2 \%$ \\
\hline
\end{tabular}




\section{Table 8: Forecasting Commodity Spot Price Changes}

The independent variables are the changes in the spot prices relative to previous quarters price on Crude Oil, Heating Oil, Gasoline, and Natural Gas. The measures of fundamental hedging demand are the average Zmijewski-score (avgZm), the average Naive EDF (avgEDF), and the negative of the average returns the last 3 years (-avg3yr) for the sample of producers in each commodity. These dependent variables are normalized to have unit variance. The data is quarterly and the dependent variables are lagged one quarter relative to the independent variables. The controls are defined in the main text of the paper, and their regression coefficients are reported here with the exception of the regression coefficients for the quarterly dummy variables. Heteroskedasticity and autocorrelation consistent standard errors (using 3 lags) are given in parentheses; *** means $p$-value $<0.01, * * p<0.05, * p<0.1$.

\begin{tabular}{|c|c|c|c|c|c|c|c|c|c|c|c|}
\hline \multicolumn{3}{|c|}{ Hedging Demand Measures } & \multicolumn{3}{|c|}{ Commodity Specific Variables } & \multicolumn{4}{|c|}{ Standard return predictors } & \multirow[b]{2}{*}{$\mathrm{N}$} & \multirow[b]{2}{*}{$\mathrm{R}^{2}$} \\
\hline avgZm & avgEDF & $-\operatorname{avg} 3 y r$ & Basis & Inventory & $\begin{array}{c}\text { Futures } \\
\text { Return }(-1)\end{array}$ & $\begin{array}{c}\Delta \text { GDP } \\
\text { forecast }\end{array}$ & $\begin{array}{c}\text { Term } \\
\text { Spread } \\
\end{array}$ & $\begin{array}{l}\text { Risk-free } \\
\text { rate }\end{array}$ & $\begin{array}{l}\text { Default } \\
\text { Spread }\end{array}$ & & \\
\hline \multicolumn{12}{|c|}{ Panel A: Crude Oil } \\
\hline $\begin{array}{c}0.054 * * \\
(0.022)\end{array}$ & & & $\begin{array}{l}-0.783 \\
(0.603)\end{array}$ & $\begin{array}{l}0.876^{*} \\
(0.455)\end{array}$ & $\begin{array}{l}-0.068 \\
(0.056)\end{array}$ & $\begin{array}{c}0.032 * * \\
(0.013)\end{array}$ & $\begin{array}{c}-5.461^{* * * *} \\
(1.701)\end{array}$ & $\begin{array}{l}-1.364 \\
(0.933)\end{array}$ & $\begin{array}{c}0.047 \\
(0.059)\end{array}$ & 91 & $24.6 \%$ \\
\hline & $\begin{array}{l}0.033^{*} \\
(0.017)\end{array}$ & & $\begin{array}{l}-0.564 \\
(0.597)\end{array}$ & $\begin{array}{c}1.292 * * \\
(0.624)\end{array}$ & $\begin{array}{c}-0.106^{*} \\
(0.067)\end{array}$ & $\begin{array}{c}0.021 \\
(0.016)\end{array}$ & $\begin{array}{c}-4.919 * * \\
(2.200)\end{array}$ & $\begin{array}{c}-0.597 \\
(1.183)\end{array}$ & $\begin{array}{c}0.045 \\
(0.069)\end{array}$ & 77 & $26.1 \%$ \\
\hline & & $\begin{array}{c}0.054 * * * \\
(0.021)\end{array}$ & $\begin{array}{l}-0.568 \\
(0.560)\end{array}$ & $\begin{array}{l}1.237 * * \\
(0.507)\end{array}$ & $\begin{array}{l}-0.087 \\
(0.059)\end{array}$ & $\begin{array}{c}0.031 * * \\
(0.014)\end{array}$ & $\begin{array}{c}-5.211 * * * \\
(1.792)\end{array}$ & $\begin{array}{c}-2.123 * * \\
(0.842)\end{array}$ & $\begin{array}{c}0.069 \\
(0.060)\end{array}$ & 91 & $24.6 \%$ \\
\hline \multicolumn{12}{|c|}{ Panel B: Heating Oil } \\
\hline $\begin{array}{l}0.035^{*} \\
(0.020)\end{array}$ & & & $\begin{array}{c}-0.255^{* * *} \\
(0.088)\end{array}$ & $\begin{array}{c}0.121 \\
(0.174)\end{array}$ & $\begin{array}{c}-0.140 * * * \\
(0.050)\end{array}$ & $\begin{array}{c}0.019^{* *} \\
(0.009)\end{array}$ & $\begin{array}{c}-3.503 * * * \\
(1.235)\end{array}$ & $\begin{array}{l}-0.557 \\
(0.779)\end{array}$ & $\begin{array}{l}-0.008 \\
(0.041)\end{array}$ & 108 & $21.8 \%$ \\
\hline & $\begin{array}{c}0.033 * * * \\
(0.012)\end{array}$ & & $\begin{array}{c}-0.196 * * * \\
(0.076)\end{array}$ & $\begin{array}{c}0.222 \\
(0.168)\end{array}$ & $\begin{array}{c}-0.148^{* * *} * \\
(0.055)\end{array}$ & $\begin{array}{l}0.014^{*} \\
(0.007)\end{array}$ & $\begin{array}{c}-2.901 * * * \\
(1.065)\end{array}$ & $\begin{array}{l}-0.022 \\
(0.740)\end{array}$ & $\begin{array}{c}-0.054^{*} \\
(0.038)\end{array}$ & 93 & $24.4 \%$ \\
\hline & & $\begin{array}{l}0.029^{*} \\
(0.015)\end{array}$ & $\begin{array}{c}-0.230 * * * \\
(0.076)\end{array}$ & $\begin{array}{c}0.189 \\
(0.176)\end{array}$ & $\begin{array}{c}-0.134 * * * \\
(0.052)\end{array}$ & $\begin{array}{c}0.018^{* *} \\
(0.009)\end{array}$ & $\begin{array}{c}-3.354 * * * \\
(1.186)\end{array}$ & $\begin{array}{l}-0.798 \\
(0.757)\end{array}$ & $\begin{array}{l}-0.016 \\
(0.040)\end{array}$ & 108 & $21.2 \%$ \\
\hline \multicolumn{12}{|c|}{ Panel C: Gasoline } \\
\hline $\begin{array}{l}0.029^{*} \\
(0.017)\end{array}$ & & & $\begin{array}{c}0.036 \\
(0.168)\end{array}$ & $\begin{array}{l}0.837^{*} \\
(0.443)\end{array}$ & $\begin{array}{c}-0.225^{* * *} \\
(0.060)\end{array}$ & $\begin{array}{c}0.033 * * * \\
(0.012\end{array}$ & $\begin{array}{c}-3.553^{* *} \\
(1.487)\end{array}$ & $\begin{array}{c}-1.423^{*} \\
(0.836)\end{array}$ & $\begin{array}{c}0.004 \\
(0.069)\end{array}$ & 88 & $26.7 \%$ \\
\hline & $\begin{array}{c}0.059 * * * \\
(0.017)\end{array}$ & & $\begin{array}{l}-0.096 \\
(0.194)\end{array}$ & $\begin{array}{c}0.588 \\
(0.399)\end{array}$ & $\begin{array}{c}-0.241^{* * *} \\
(0.065)\end{array}$ & $\begin{array}{c}0.011 \\
(0.014)\end{array}$ & $\begin{array}{c}-0.557 \\
(1.482)\end{array}$ & $\begin{array}{c}1.124 \\
(1.184)\end{array}$ & $\begin{array}{l}-0.040 \\
(0.076)\end{array}$ & 74 & $27.3 \%$ \\
\hline & & $\begin{array}{c}0.023 \\
(0.017)\end{array}$ & $\begin{array}{c}0.041 \\
(0.163)\end{array}$ & $\begin{array}{l}0.865^{*} \\
(0.449)\end{array}$ & $\begin{array}{c}-0.222 * * * \\
(0.060)\end{array}$ & $\begin{array}{c}0.029 * * \\
(0.013)\end{array}$ & $\begin{array}{l}-3.169^{*} \\
(1.632)\end{array}$ & $\begin{array}{c}-1.613^{* *} \\
(0.780)\end{array}$ & $\begin{array}{c}0.013 \\
(0.069)\end{array}$ & 88 & $26.0 \%$ \\
\hline \multicolumn{12}{|c|}{ Panel D: Natural Gas } \\
\hline $\begin{array}{c}0.057 \\
(0.039)\end{array}$ & & & $\begin{array}{l}-0.078 \\
(0.248)\end{array}$ & $\begin{array}{c}0.120 \\
(0.223)\end{array}$ & $\begin{array}{c}-0.195^{*} \\
(0.115)\end{array}$ & $\begin{array}{c}0.062 \\
(0.040)\end{array}$ & $\begin{array}{l}-1.431 \\
(5.113)\end{array}$ & $\begin{array}{l}-0.332 \\
(2.274)\end{array}$ & $\begin{array}{c}0.117 \\
(0.117)\end{array}$ & 64 & $17.2 \%$ \\
\hline & $\begin{array}{c}0.010 \\
(0.038)\end{array}$ & & $\begin{array}{l}-0.276 \\
(0.299)\end{array}$ & $\begin{array}{c}0.245 \\
(0.279)\end{array}$ & $\begin{array}{l}-0.196 \\
(0.154)\end{array}$ & $\begin{array}{l}0.090^{*} \\
(0.055)\end{array}$ & $\begin{array}{l}-7.001 \\
(6.584)\end{array}$ & $\begin{array}{l}-0.952 \\
(2.452)\end{array}$ & $\begin{array}{c}0.258 \\
(0.166)\end{array}$ & 50 & $20.6 \%$ \\
\hline & & $\begin{array}{c}0.089^{* *} \\
(0.041)\end{array}$ & $\begin{array}{l}-0.140 \\
(0.246)\end{array}$ & $\begin{array}{c}0.305 \\
(0.244)\end{array}$ & $\begin{array}{l}-0.174 \\
(0.122)\end{array}$ & $\begin{array}{l}0.072 * \\
(0.041)\end{array}$ & $\begin{array}{l}-6.014 \\
(4.900)\end{array}$ & $\begin{array}{l}-2.099 \\
(2.080)\end{array}$ & $\begin{array}{c}0.083 \\
(0.112)\end{array}$ & 64 & $21.4 \%$ \\
\hline \multicolumn{12}{|c|}{ Panel E: Pooled Regression } \\
\hline $\begin{array}{c}0.037^{* *} \\
(0.016)\end{array}$ & & & $\begin{array}{c}-0.328 * * * \\
(0.065)\end{array}$ & $\begin{array}{c}0.034 \\
(0.082)\end{array}$ & $\begin{array}{c}-0.150^{* * *} \\
(0.029)\end{array}$ & $\begin{array}{c}0.026^{* *} \\
(0.010)\end{array}$ & $\begin{array}{c}-3.319^{* * *} \\
(1.064)\end{array}$ & $\begin{array}{l}-0.948 \\
(0.777)\end{array}$ & $\begin{array}{c}0.010 \\
(0.044)\end{array}$ & 351 & $15.2 \%$ \\
\hline & $\begin{array}{c}0.033 * * * \\
(0.011)\end{array}$ & & $\begin{array}{c}-0.358 * * * \\
(0.041)\end{array}$ & $\begin{array}{c}0.034 \\
(0.100)\end{array}$ & $\begin{array}{c}-0.145 * * * \\
(0.023)\end{array}$ & $\begin{array}{c}0.018 * * \\
(0.009)\end{array}$ & $\begin{array}{c}-2.820 * * \\
(1.190)\end{array}$ & $\begin{array}{l}-0.318 \\
(0.840)\end{array}$ & $\begin{array}{l}-0.017 \\
(0.046)\end{array}$ & 294 & $16.7 \%$ \\
\hline & & $\begin{array}{c}0.037 * * \\
(0.016)\end{array}$ & $\begin{array}{c}-0.320 * * * \\
(0.050)\end{array}$ & $\begin{array}{c}0.067 \\
(0.085)\end{array}$ & $\begin{array}{c}-0.149 * * * \\
(0.026)\end{array}$ & $\begin{array}{c}0.025^{* *} \\
(0.010)\end{array}$ & $\begin{array}{c}-3.558 * * * \\
(1.308)\end{array}$ & $\begin{array}{c}-1.308^{*} \\
(0.763)\end{array}$ & $\begin{array}{c}0.017 \\
(0.045)\end{array}$ & 351 & $15.3 \%$ \\
\hline
\end{tabular}




\section{Table 9: Hedging Demand and Speculator Risk Tolerance}

The independent variables are aggregate inventory above trend value, futures return, and net spot price change for Crude Oil, Heating Oil, Gasoline, and Natural Gas. The regressions are pooled across the four commodities. The measures of fundamental hedging demand are the average Zmijewski-score (avgZm), the average Naive EDF (avgEDF), and the negative of the average returns the last 3 years (-avg3yr) for the sample of producers in each commodity. The measures of speculator risk tolerance are growth in aggregate BrokerDealer assets (BD_measure) and growth in Commodity Trading Advisor's assets under management (CTA measure); both minus the aggregate growth in household assets. The dependent variables are normalized to have unit variance. The data is quarterly and the dependent variables are lagged one quarter relative to the independent variables., except for inventory which is annual and where the lag is one year. The controls are described in the main text in the paper. Heteroskedasticity and autocorrelation consistent standard errors (using 3 lags) are given in parentheses; *** means $p$-value $<0.01$, ** $p<0.05$, * $p<0.1$.

\begin{tabular}{|c|c|c|c|c|c|c|}
\hline \multirow[b]{2}{*}{$\begin{array}{c}\text { Pooled } \\
\text { torecasting regs: }\end{array}$} & \multicolumn{3}{|c|}{$\underline{B-D}$ measure } & \multicolumn{3}{|c|}{ CTA measure } \\
\hline & $\begin{array}{c}\text { Futures } \\
\text { return }\end{array}$ & $\begin{array}{c}\text { Spot } \\
\% \text {-change } \\
\end{array}$ & $\begin{array}{c}\text { Annual } \\
\text { Inventory }\end{array}$ & $\begin{array}{c}\text { Futures } \\
\text { return }\end{array}$ & $\begin{array}{c}\text { Spot } \\
\% \text {-change } \\
\end{array}$ & $\begin{array}{c}\text { Annual } \\
\text { Inventory }\end{array}$ \\
\hline Spec_measure & $\begin{array}{c}-0.059 * * * \\
(0.013)\end{array}$ & $\begin{array}{c}-0.062^{* * *} \\
(0.016)\end{array}$ & $\begin{array}{c}0.015^{* * * *} \\
(0.005)\end{array}$ & $\begin{array}{c}-0.072 * * * \\
(0.011)\end{array}$ & $\begin{array}{c}-0.053^{* * *} \\
(0.010)\end{array}$ & $\begin{array}{c}0.023^{* * *} \\
(0.005)\end{array}$ \\
\hline avgZm & $\begin{array}{l}0.034^{*} \\
(0.019)\end{array}$ & $\begin{array}{c}0.022 \\
(0.016)\end{array}$ & $\begin{array}{c}-0.023^{* *} \\
(0.010)\end{array}$ & $\begin{array}{c}0.069 * * * \\
(0.021)\end{array}$ & $\begin{array}{c}0.033 * * \\
(0.015)\end{array}$ & $\begin{array}{c}-0.033^{*} \\
(0.018)\end{array}$ \\
\hline $\begin{array}{c}\mathrm{R}^{2} \\
\text { \# obs }\end{array}$ & $\begin{array}{l}17.1 \% \\
343\end{array}$ & $\begin{array}{c}22.0 \% \\
351\end{array}$ & $\begin{array}{c}75.8 \% \\
331\end{array}$ & $\begin{array}{c}19.1 \% \\
200\end{array}$ & $\begin{array}{c}11.4 \% \\
200\end{array}$ & $\begin{array}{c}79.0 \% \\
188\end{array}$ \\
\hline Spec_measure & $\begin{array}{c}-0.058 * * * \\
(0.014)\end{array}$ & $\begin{array}{c}-0.061 * * * \\
(0.017)\end{array}$ & $\begin{array}{c}0.014^{* * *} \\
(0.004)\end{array}$ & $\begin{array}{c}-0.061 * * * \\
(0.017)\end{array}$ & $\begin{array}{c}-0.035^{* *} \\
(0.017)\end{array}$ & $\begin{array}{l}0.015^{*} \\
(0.009)\end{array}$ \\
\hline avgEDF & $\begin{array}{c}0.025 * * \\
(0.009)\end{array}$ & $\begin{array}{c}0.022^{* * *} \\
(0.008)\end{array}$ & $\begin{array}{c}-0.034^{* * *} \\
(0.007)\end{array}$ & $\begin{array}{c}0.038 * * * \\
(0.013)\end{array}$ & $\begin{array}{c}0.029 * * * \\
(0.009)\end{array}$ & $\begin{array}{c}-0.058 * * * \\
(0.017)\end{array}$ \\
\hline $\begin{array}{c}\mathrm{R}^{2} \\
\text { \# obs }\end{array}$ & $\begin{array}{c}15.6 \% \\
287\end{array}$ & $\begin{array}{c}22.6 \% \\
294\end{array}$ & $\begin{array}{c}76.9 \% \\
287\end{array}$ & $\begin{array}{c}22.8 \% \\
144\end{array}$ & $\begin{array}{c}18.1 \% \\
144\end{array}$ & $\begin{array}{c}81.0 \% \\
144\end{array}$ \\
\hline Spec_measure & $\begin{array}{c}-0.063 * * * \\
(0.010)\end{array}$ & $\begin{array}{c}-0.065^{* * *} \\
(0.014)\end{array}$ & $\begin{array}{c}0.019 * * \\
(0.007)\end{array}$ & $\begin{array}{c}-0.070 * * * \\
(0.012)\end{array}$ & $\begin{array}{c}-0.052 * * * \\
(0.010)\end{array}$ & $\begin{array}{c}0.019 * * * \\
(0.004)\end{array}$ \\
\hline -avg3yr & $\begin{array}{c}0.051^{* * *} \\
(0.016)\end{array}$ & $\begin{array}{c}0.032 * * \\
(0.015)\end{array}$ & $\begin{array}{l}-0.008 \\
(0.011)\end{array}$ & $\begin{array}{c}0.070 * * * \\
(0.019)\end{array}$ & $\begin{array}{l}0.031^{*} \\
(0.018)\end{array}$ & $\begin{array}{l}-0.010 \\
(0.013)\end{array}$ \\
\hline $\begin{array}{c}\mathrm{R}^{2} \\
\# \text { obs }\end{array}$ & $\begin{array}{c}19.5 \% \\
343\end{array}$ & $\begin{array}{c}23.0 \% \\
351\end{array}$ & $\begin{array}{l}75.1 \% \\
331\end{array}$ & $\begin{array}{c}20.1 \% \\
200\end{array}$ & $\begin{array}{l}11.3 \% \\
200\end{array}$ & $\begin{array}{c}78.0 \% \\
188\end{array}$ \\
\hline Controls? & yes & yes & yes & yes & yes & yes \\
\hline
\end{tabular}




\section{Figure 1 - Model Predictions}

All plots have producer fundamental hedging demand $\left(\gamma_{p} \in\{2,4, \ldots, 20\}\right)$ on the horizontal axis. The dashed line corresponds to high speculator capital constraints $\left(\gamma_{\mathrm{s}}=40\right)$, while the solid line is the case of low speculator capital constraints $\left(\left(\gamma_{s}=8\right)\right)$. The two top plots show the cost of hedging as a proportion of firm value (left) and the quarterly Sharpe ratio of the abnormal returns earned by speculators. The two middle plots show (on the left) the component of the futures risk premium due to the covariance with the equity market pricing kernel and (on the right) the component due to the combination of hedging pressure and limits to arbitrage. The two lowest graphs show the expected spot price change relative to the current spot price and the optimal inventory. The numbers used in the calibration of the model are given and explained in main text.

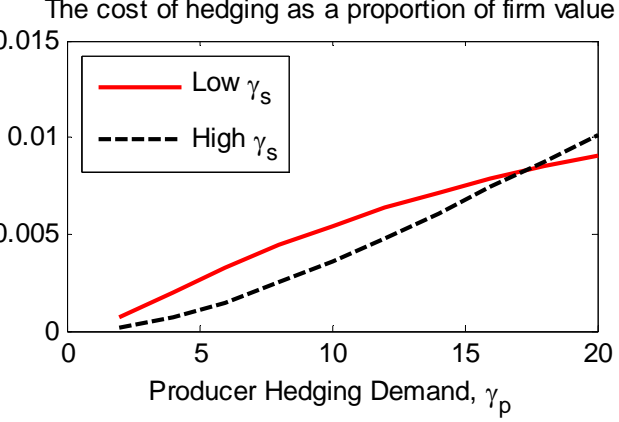

The futures risk premium: Covariance component

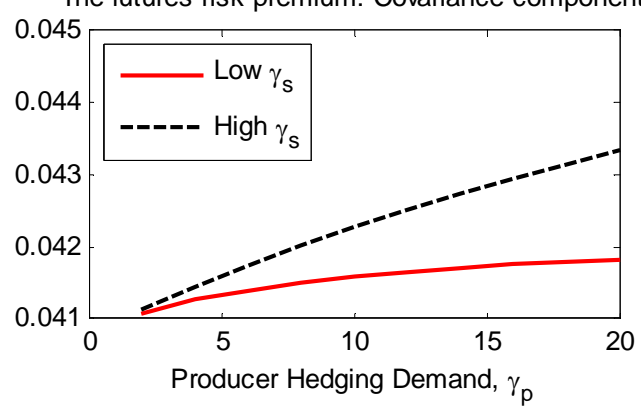

The spot risk premium

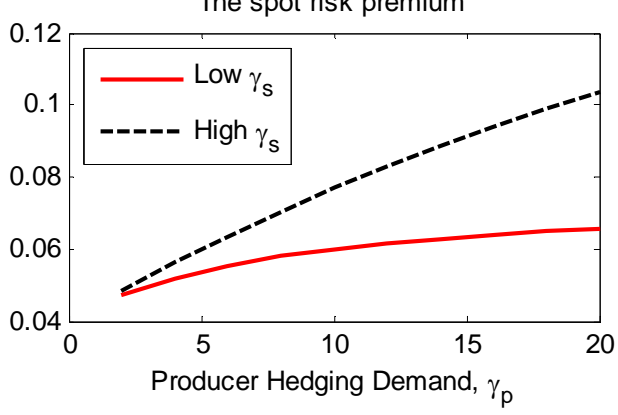

The SR of the abnormal futures return

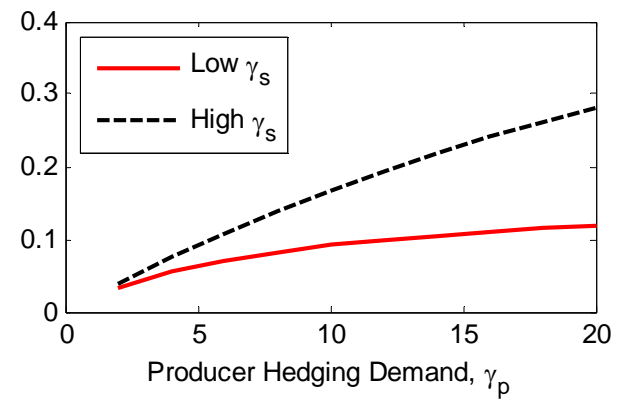

FRP Component due to LimitsToArb+HedgingPressure
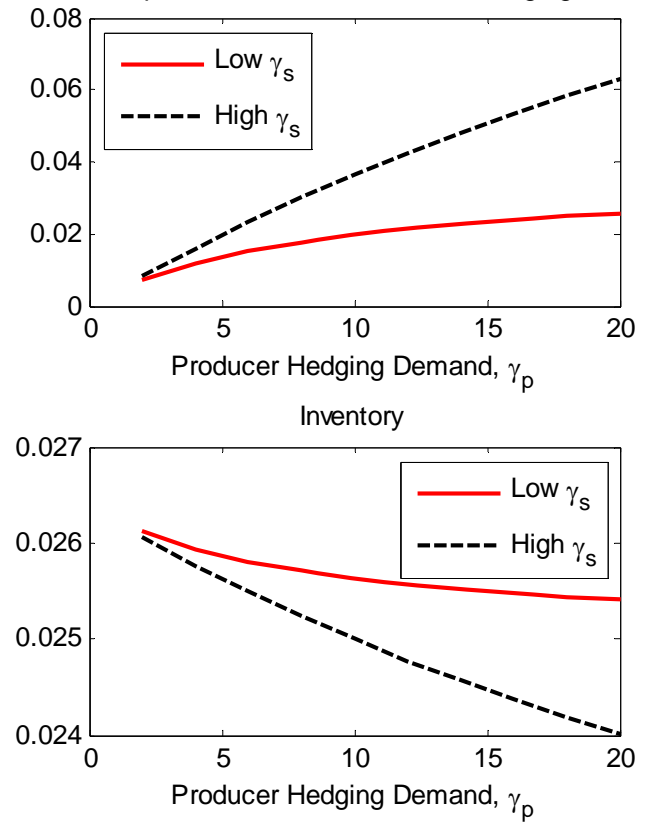


\section{Figure 2a - Aggregate Default Risk Measures (I)}

This figure plots the default risk measures (AVG3Y, AVGZm and Naïve EDF) for Crude Oil, Heating Oil and Gasoline (the series used for all three commodities are the same, since the producer firms are in the same SIC classification codes). The series are normalized by subtracting their means and dividing by their standard deviations for ease of plotting.

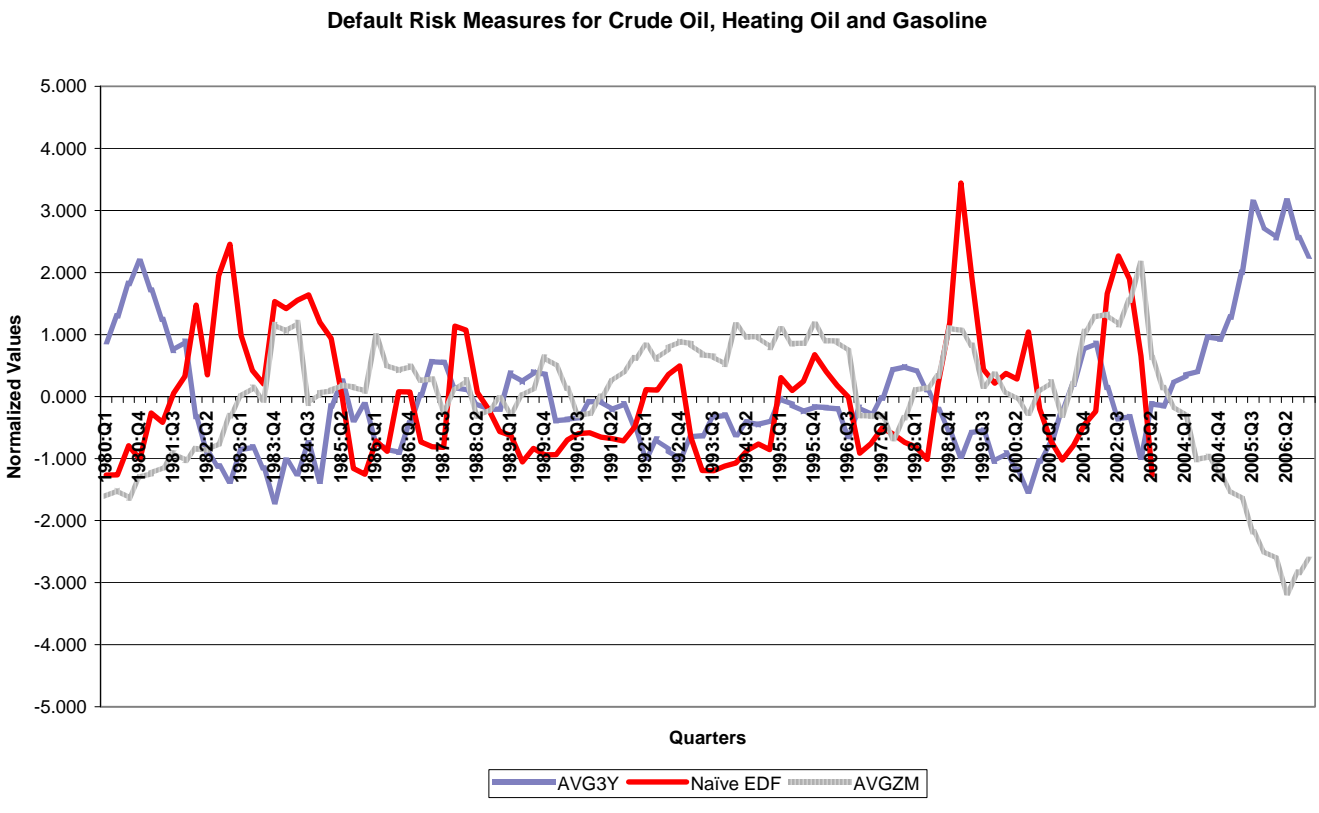

Figure 2b - Aggregate Default Risk Measures (II)

This figure plots the default risk measures (AVG3Y, AVGZm and Naïve EDF) for Natural Gas producers. The series are normalized by subtracting their means and dividing by their standard deviations for ease of plotting.

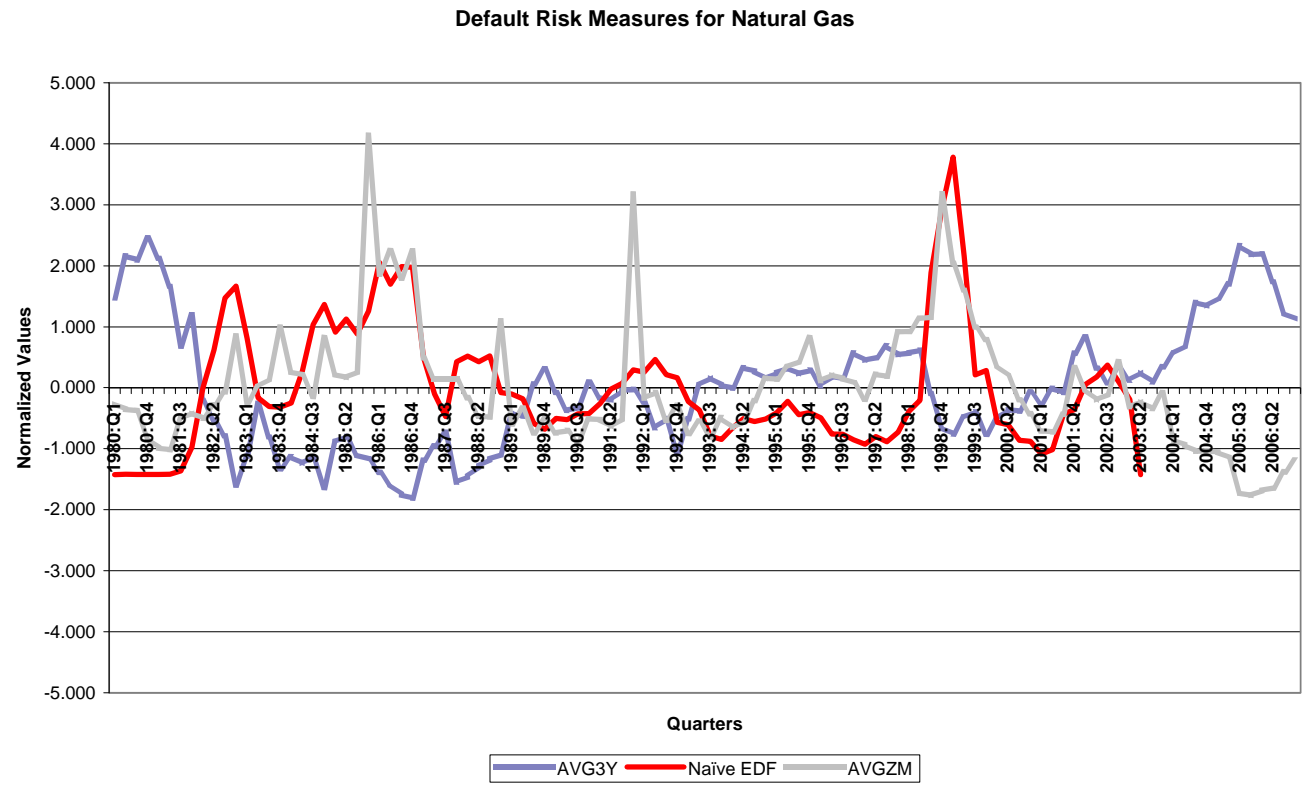




\section{Figure 3a - Firm Crude Oil Hedging and the Zmijewski-score}

The plots show short hedging, measured as the negative of the Delta of their current crude oil derivatives positions, for the four firms in the sample where a minimal time series of observations are available, relative to each firm's Zmijewski-score. Each series, for each firm, is normalized to have zero mean and unit variance to facilitate easy comparison.

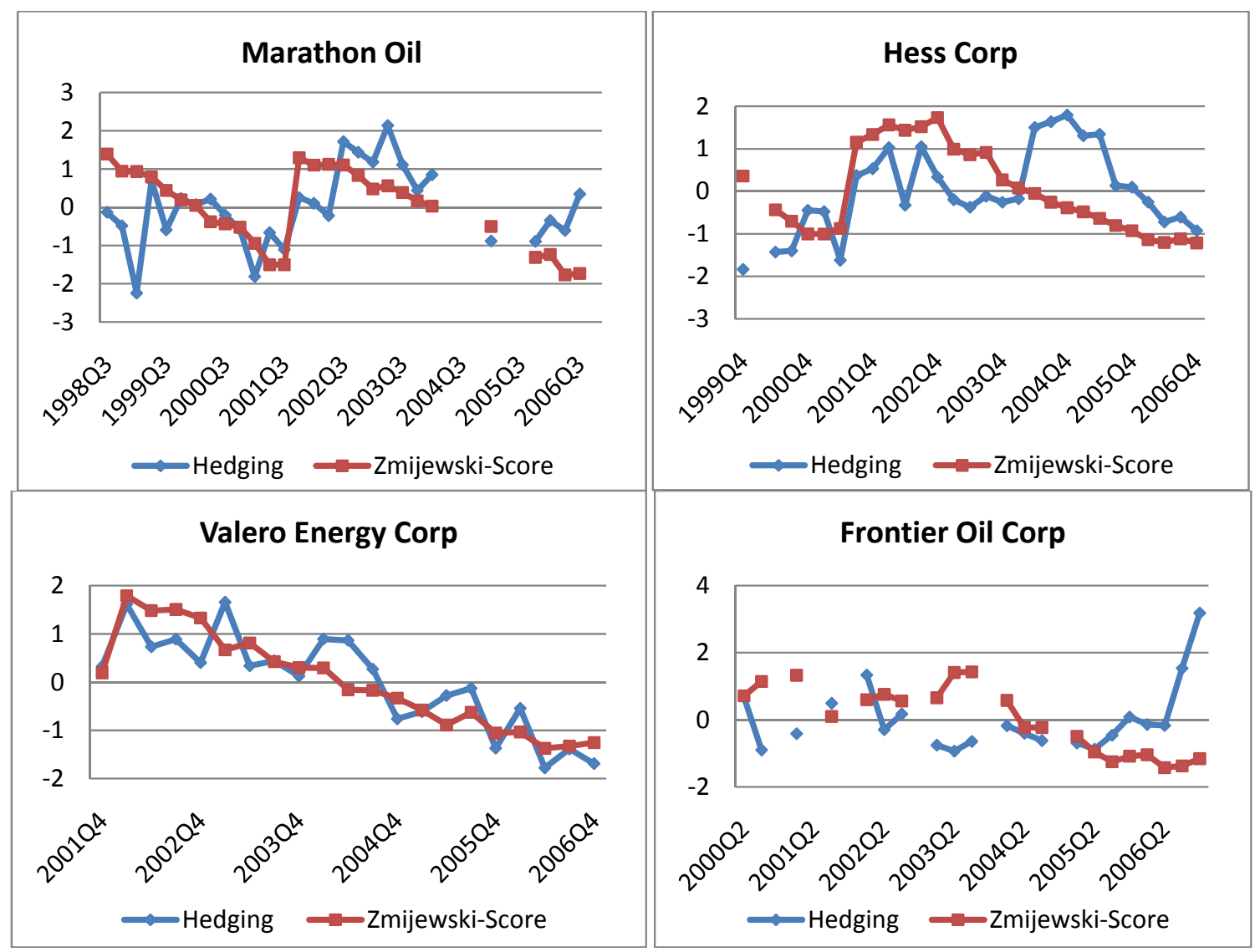


Figure 3b - Firm Crude Oil Hedging and the Negative of the 3 Year Average Stock Return

The plots show short hedging, measured as the negative of the Delta of their current crude oil derivatives positions, for the four firms in the sample where a minimal time series of observations are available, relative to the negative of each firm's 3 year lagged returns. Each series, for each firm, is normalized to have zero mean and unit variance to facilitate easy comparison.

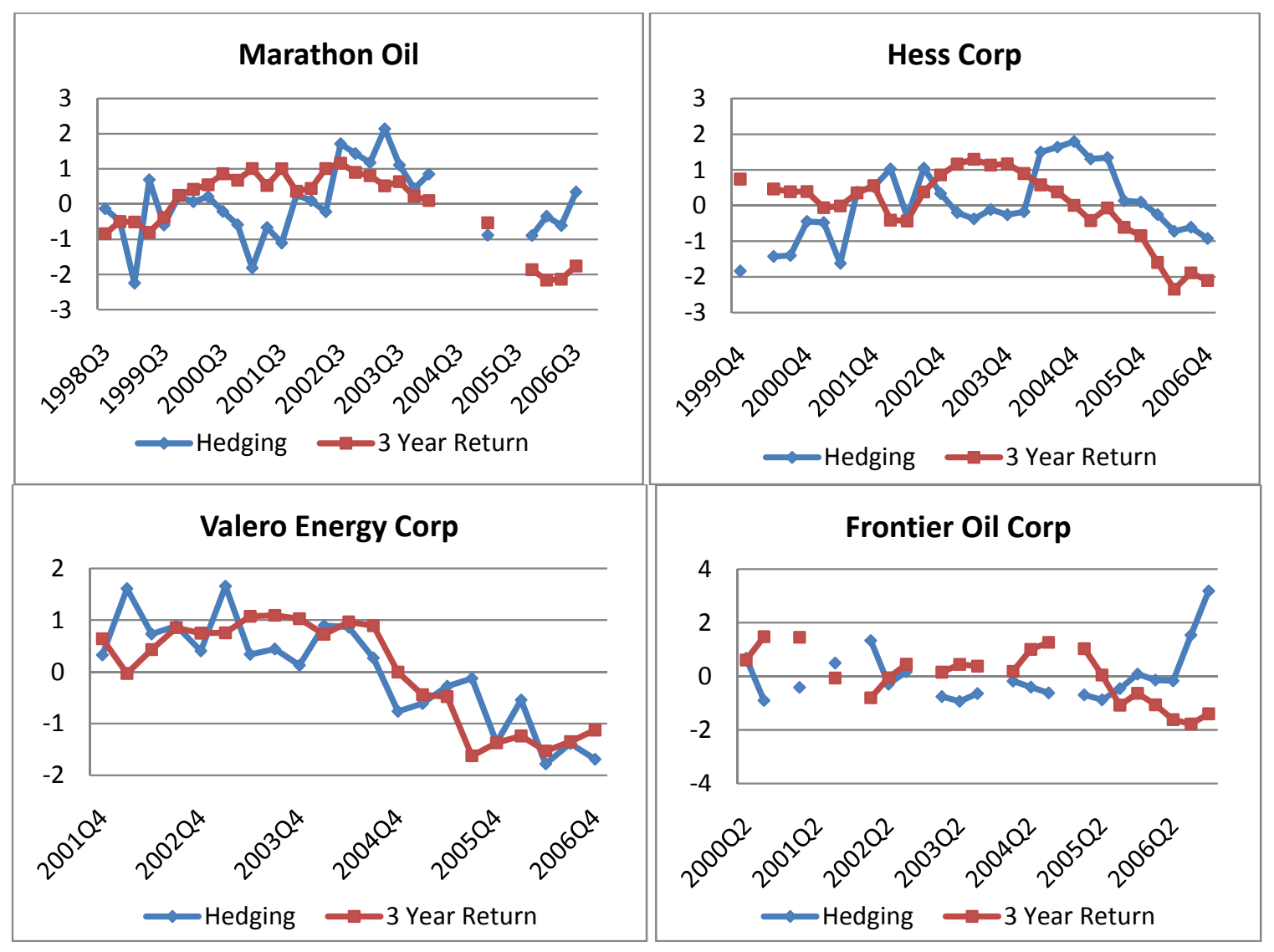




\section{Figure 3c - Valero Hedging and CDS spread}

The plot shows short hedging, measured as the negative of the Delta of Valero's current crude oil derivatives positions versus its current 5 year credit default swap spread. Both series are normalized to have zero mean and unit variance to facilitate easy comparison.

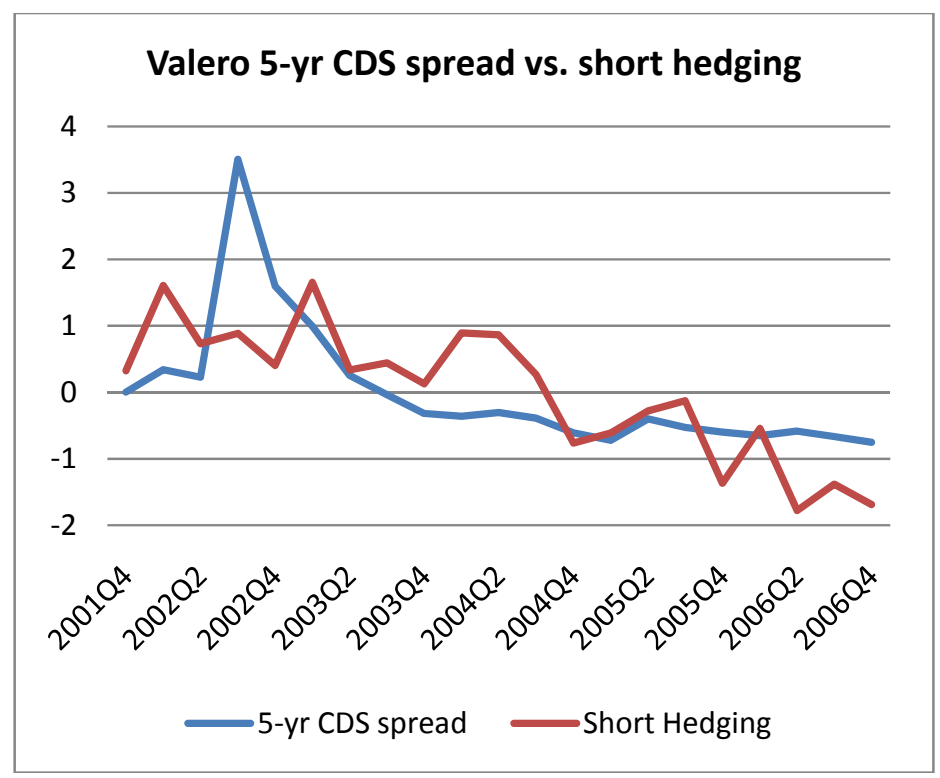


Figure 4 - Hedging versus Arbitrage Activity

The graphs show the proportion of the commodity futures' risk premiums due to hedging demand versus the amount of arbitrage activity. The measure of hedging demand is an average of the three measures used in the paper (aggregate producer Zmijewski-score, naive EDF, and (the negative of) 3-year lagged stock returns), as explained in the main text. The measure of arbitrage activity is the growth in aggregate Broker-Dealer (two top plots) or Commodity Trading Advisors (CTAs; bottom plot) assets relative to the growth in aggregate household assets.
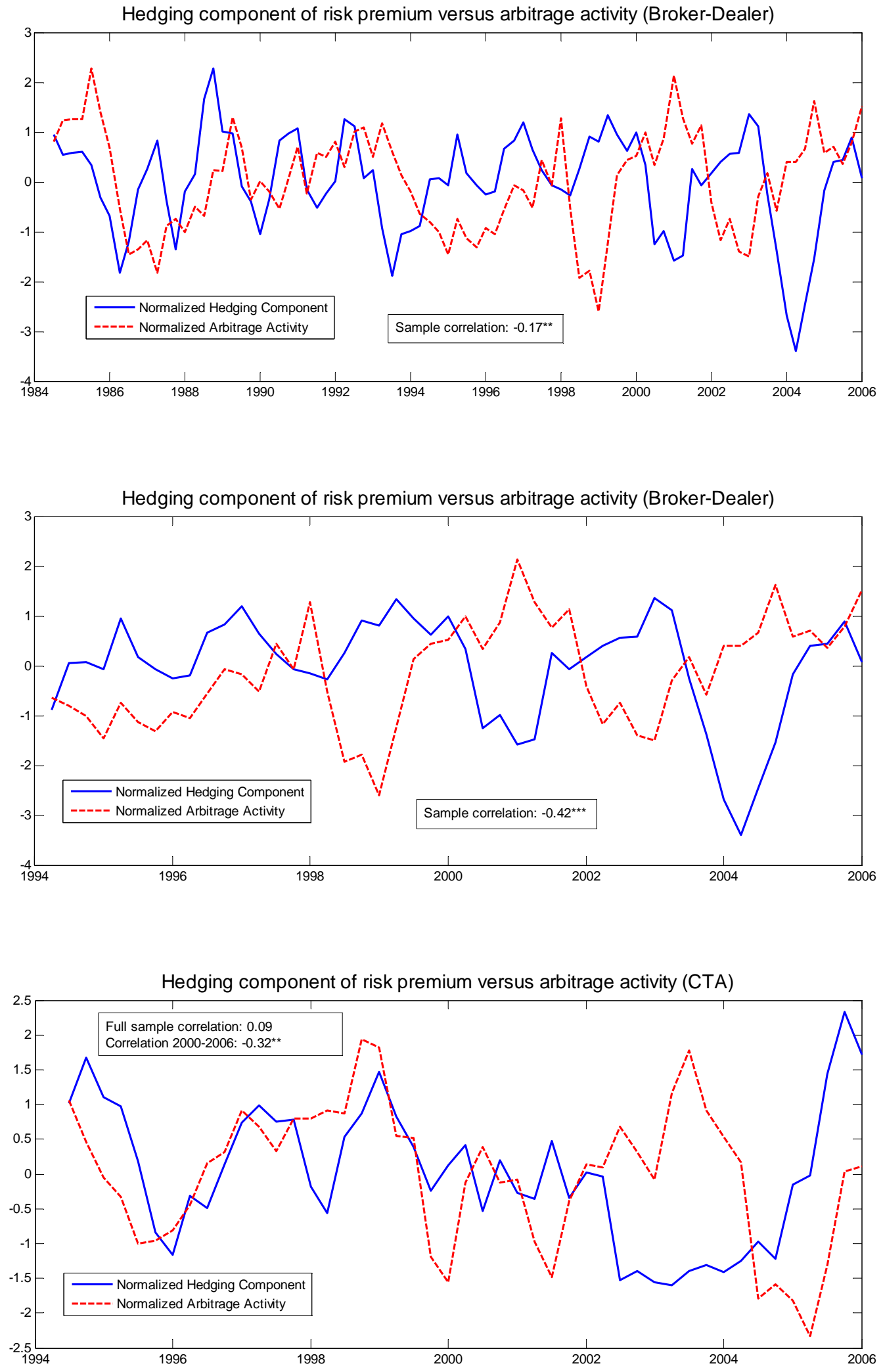


\section{Appendix}

\section{A. Calibration}

We calibrate the model using the volatility of the commodity futures returns, commodity expenditure relative to aggregate endowment (GDP) and aggregate endowment growth, as well as the mean and volatility of the equity market pricing kernel. All moments are quarterly, corresponding to the empirical exercise in the next section. We calibrate the demand shock $A_{1}$ to roughly correspond with aggregate GDP growth and set $\mu=0.004, \sigma=0.02$ and the initial demand shock $A_{0}=1$. We set the depreciation rate, $\delta$, to 0.01 . Further, we assume the $\log$ stochastic discount factor $(\Lambda)$ has a quarterly volatility of $20 \%$ and a mean of $-0.25 \%$, corresponding roughly to an annual equity Sharpe ratio of 0.4 and a risk-free rate of $1 \%$. We let the stochastic discount factor be perfectly negatively correlated with the demand shocks. Next, we calibrate the intratemporal elasticity of substitution $\varepsilon$ and the constant $\omega$ jointly such that the standard deviation of futures returns $\left(S_{1}-F\right) / F$ is about $20 \%$ per quarter, as in the data, and the average commodity expenditure is about $10 \%$ of expenditures on other goods. Given the volatility of demand shocks, this is achieved when $\varepsilon=0.1$ and $\omega=0.01$. That is, consumers are relatively inelastic in terms of substituting the commodity good for other goods, which is reasonable given our focus on oil and gas in the empirical section. ${ }^{23}$ We let period 0 and period 1 production, $g_{0}$ and $g_{1}$, be 0.8 and 0.75 , respectively, such that inventory holdings are positive.

The severity of the model's frictions are increasing in the variance aversion of producers and speculators, $\gamma_{p}$ and $\gamma_{s}$. As we posit mean-variance preferences, the values of these coefficients do not directly correspond to easily-interpretable magnitudes (such as might be the case with relative risk aversion). We therefore use the following two economic measures to calibrate a reasonable range for each of these parameters. First, we let the loss to the firm from hedging, $h^{*} E\left[\Lambda\left(S_{1}-F\right)\right]$, be between $0.1 \%$ and $1 \%$ of firm value and, second, we let the abnormal quarterly Sharpe ratio earned by speculators be between 0.05 and 0.25. The variation in these quantities is shown in the two top graphs of Figure 1 , where $\gamma_{p} \in\{2,4, \ldots, 20\}$ on the horizontal axis and $\gamma_{s} \in\{8,40\}$ is shown as a dashed line for high speculator risk aversion and a solid line for low speculator risk aversion.

\section{B. Proofs of results given in the main body of paper}

It is useful to establish some preliminary results. Note that for the futures market to clear when $\gamma_{p}, \gamma_{s}>0$, the condition $E\left[\Lambda\left(S_{1}-F\right)\right]>0$ must be satisfied (see Equation (9)). Since this implies that $h_{p}^{*}<I(1-\delta)+g_{1}$ (see Equation (4)), we have from Equation (3) that $E\left[\Lambda S_{1}\right]-S_{0} /(1-\delta)>0$ when there is no stock-out $(\lambda=0)$.

\section{B.1. Proof of Proposition 1}

The consumer demand function is given by

$$
S_{t}=\omega\left(\frac{A_{t}}{Q_{t}}\right)^{1 / \varepsilon}=\omega Q_{t}^{-1 / \varepsilon} e^{\frac{1}{\varepsilon} a_{t}} .
$$

where the $\log$ of the demand shock $A_{t}\left(a_{t}\right)$ is distributed $N\left(\mu, \sigma^{2}\right)$ and where $Q_{t}$ is the equilibrium commodity supply at time $t$. Since $Q_{t}$ is predetermined, the variance of the period 1 spot price conditional on period 0 information is:

$$
\sigma_{S}^{2}=Q_{1}^{-2 / \varepsilon} k
$$

where $k \equiv \omega^{2}\left(e^{(\sigma / \varepsilon)^{2}}-1\right) e^{2 \mu / \varepsilon+(\sigma / \varepsilon)^{2}}$.

\footnotetext{
${ }^{23}$ This also justifies our implicit model assumption that price risk outweighs quantity risk for the producers. As pointed out by, e.g., Hirshleifer (1988), if the opposite is the case, producers would hedge by going long the futures contract.
} 
First, consider the case of no stock-out, $\lambda=0$. In this case, we have from the equilibrium condition given in Equation (10) that:

$$
Q_{1}^{2 / \varepsilon}\left(E\left[\Lambda S_{1}\left(I^{*}\right)\right]-S_{0}\left(I^{*}\right) /(1-\delta)\right)=\frac{\gamma_{p} \gamma_{s}}{\gamma_{p}+\gamma_{s}} k Q_{1}
$$

Taking the total derivative of Equation (29) with respect to producer default risk, we have:

$$
\begin{gathered}
\frac{2}{\varepsilon} Q_{1}^{2 / \varepsilon-1} \frac{\partial Q_{1}}{\partial I} \frac{d I}{d \gamma_{p}}\left(E\left[\Lambda S_{1}\right]-S_{0} /(1-\delta)\right)+Q_{1}^{2 / \varepsilon}\left(E\left[\Lambda \frac{\partial S_{1}}{\partial I} \frac{d I}{d \gamma_{p}}\right]-\frac{\partial S_{0}}{\partial I} \frac{d I}{d \gamma_{p}} /(1-\delta)\right) \\
\ldots=\frac{\gamma_{s}^{2}}{\left(\gamma_{p}+\gamma_{s}\right)^{2}} k Q_{1}+\frac{\gamma_{p} \gamma_{s}}{\gamma_{p}+\gamma_{s}} k \frac{\partial Q_{1}}{\partial I} \frac{d I}{d \gamma_{p}} . \\
\Uparrow \\
\frac{-\frac{\gamma_{s}^{2}}{\left(\gamma_{p}+\gamma_{s}\right)^{2}} k Q_{1}}{\frac{\gamma_{p} \gamma_{s}}{\gamma_{p}+\gamma_{s}} k(1-\delta)-Q_{1}^{2 / \varepsilon}\left(E\left[\Lambda \frac{\partial S_{1}}{\partial I}\right]-\frac{\partial S_{0}}{\partial I} /(1-\delta)\right)-\frac{2}{\varepsilon} Q_{1}^{2 / \varepsilon-1}(1-\delta)\left[E\left[\Lambda S_{1}\right]-S_{0} /(1-\delta)\right]}=\frac{d I}{d \gamma_{p}} .
\end{gathered}
$$

In this calculation, we are assuming that the pricing kernel $\Lambda$ is not affected by changes in inventory. Given the inverse demand function, $\frac{d S_{1}}{d I}<0$ and $\frac{d S_{0}}{d I}>0$, and therefore $E\left[\Lambda \frac{d S_{1}}{d I}\right]-\frac{d S_{0}}{d I} /(1-\delta)<0$. Also, as noted in the preliminary results above, $E\left[\Lambda S_{1}\right]-S_{0} /(1-\delta)>0$. Since $S_{t}=\omega Q_{t}^{-1 / \varepsilon} e^{\frac{1}{\varepsilon} a_{t}}$, and since $Q_{0}=G_{0}-I$ and $Q_{1}=G_{1}+(1-\delta) I$, we have that:

$$
\begin{aligned}
& \frac{\partial S_{1}}{\partial I}=-\frac{1}{\varepsilon} \omega e^{\frac{1}{\varepsilon} a_{1}} Q_{1}^{-1 / \varepsilon-1}(1-\delta)<0 \\
& \frac{\partial S_{0}}{\partial I}=\frac{1}{\varepsilon} \omega e^{\frac{1}{\varepsilon} a_{0}} Q_{0}^{-1 / \varepsilon-1}>0
\end{aligned}
$$

Thus,

$$
E\left[\Lambda \frac{\partial S_{1}}{\partial I}\right]-\frac{\partial S_{0}}{\partial I} /(1-\delta)=-\frac{1}{\varepsilon} \omega Q_{1}^{-1 / \varepsilon-1}(1-\delta) E\left[\Lambda e^{\frac{1}{\varepsilon} a_{1}}\right]-\frac{1}{\varepsilon} \omega e^{\frac{1}{\varepsilon} a_{0}} Q_{0}^{-1 / \varepsilon-1} /(1-\delta)
$$

and

$$
E\left[\Lambda S_{1}\right]-S_{0} /(1-\delta)=\omega Q_{1}^{-1 / \varepsilon} E\left[\Lambda e^{\frac{1}{\varepsilon} a_{1}}\right]-\omega Q_{0}^{-1 / \varepsilon} e^{\frac{1}{\varepsilon} a_{0}} /(1-\delta)
$$

Focusing on the sign of the two last terms in the denominator on the left hand side of Equation (31), and substituting in the expressions from Equations (34) and (35), we have that:

$$
\begin{gathered}
-Q_{1}^{2 / \varepsilon}\left(E\left[\Lambda \frac{\partial S_{1}}{\partial I}\right]-\frac{\partial S_{0}}{\partial I} /(1-\delta)\right)-\frac{2}{\varepsilon} Q_{1}^{2 / \varepsilon-1}(1-\delta)\left[E\left[\Lambda S_{1}\right]-S_{0} /(1-\delta)\right]=\ldots \\
\frac{1}{\varepsilon} \omega Q_{1}^{1 / \varepsilon-1}(1-\delta) E\left[\Lambda e^{\frac{1}{\varepsilon} a_{1}}\right]+\frac{1}{\varepsilon} \omega e^{\frac{1}{\varepsilon} a_{0}} Q_{1}^{2 / \varepsilon} Q_{0}^{-1 / \varepsilon-1} /(1-\delta)-\frac{2}{\varepsilon} Q_{1}^{1 / \varepsilon-1}(1-\delta) \omega E\left[\Lambda e^{\left.\frac{1}{\varepsilon} a_{1}\right]}+\frac{2}{\varepsilon} \omega Q_{1}^{2 / \varepsilon-1} Q_{0}^{-1 / \varepsilon} e^{\frac{1}{\varepsilon} a_{0}}\right. \\
=\frac{1}{\varepsilon} \omega e^{\frac{1}{\varepsilon} a_{0}} Q_{1}^{2 / \varepsilon} Q_{0}^{-1 / \varepsilon-1}\left(\frac{1}{1-\delta}+2 Q_{1}^{-1} Q_{0}\right)-\frac{1}{\varepsilon} \omega Q_{1}^{1 / \varepsilon-1}(1-\delta) E\left[\Lambda e^{\frac{1}{\varepsilon} a_{1}}\right] \\
=\frac{\omega}{\varepsilon} Q_{1}^{1 / \varepsilon-1}\left(e^{\frac{1}{\varepsilon} a_{0}}\left(Q_{1} / Q_{0}\right)^{1 / \varepsilon+1}\left(\frac{1}{1-\delta}+2 Q_{0} / Q_{1}\right)-(1-\delta) E\left[\Lambda e^{\frac{1}{\varepsilon} a_{1}}\right]\right) .
\end{gathered}
$$

We still cannot sign this term. However, we can use the following relations to get us the final step. Since $(1-\delta) E\left[\Lambda S_{1}\right]-S_{0}>0$, 
using the inverse demand function, it follows that

$$
\begin{aligned}
(1-\delta) E\left[\Lambda e^{\frac{1}{\varepsilon} a_{1}}\right]- & \left(Q_{1} / Q_{0}\right)^{1 / \varepsilon} e^{\frac{1}{\varepsilon} a_{0}}>0 . \\
& (1-\delta) E\left[\Lambda e^{\frac{1}{\varepsilon} a_{1}}\right]>\left(Q_{1} / Q_{0}\right)^{1 / \varepsilon} e^{\frac{1}{\varepsilon} a_{0}}>0 .
\end{aligned}
$$

Using this inequality to sign Equation (36), we have that:

$$
\begin{aligned}
\frac{\omega}{\varepsilon} Q_{1}^{1 / \varepsilon-1}\left(e^{\frac{1}{\varepsilon} a_{0}}\left(Q_{1} / Q_{0}\right)^{1 / \varepsilon+1}\left(\frac{1}{1-\delta}+2 Q_{0} / Q_{1}\right)-(1-\delta) E\left[\Lambda e^{\frac{1}{\varepsilon} a_{1}}\right]\right) & >\ldots \\
\frac{\omega}{\varepsilon} Q_{1}^{1 / \varepsilon-1}\left(e^{\frac{1}{\varepsilon} a_{0}}\left(Q_{1} / Q_{0}\right)^{1 / \varepsilon+1}\left(\frac{1}{1-\delta}+2 Q_{0} / Q_{1}\right)-\left(Q_{1} / Q_{0}\right)^{1 / \varepsilon} e^{\frac{1}{\varepsilon} a_{0}}\right) & =\ldots \\
\frac{\omega}{\varepsilon} Q_{1}^{1 / \varepsilon-1} e^{\frac{1}{\varepsilon} a_{0}}\left(Q_{1} / Q_{0}\right)^{1 / \varepsilon}\left(\frac{Q_{1}}{Q_{0}} \frac{1}{1-\delta}+1\right) & >0 .
\end{aligned}
$$

Thus, referring now back to Equation (31), $\frac{d I}{d \gamma_{p}}<0$. In the case of an inventory stock-out, we have trivially that $\frac{d I}{d \gamma_{p}}=\frac{d I}{d \gamma_{s}}=0$.

The derivative of the expected spot return with respect to producer risk aversion is then:

$$
\begin{aligned}
\frac{d}{d \gamma_{p}} \frac{E\left[S_{1}\right]-S_{0}}{S_{0}} & =\frac{\left(E\left[\frac{d S_{1}}{d I} \frac{d I}{d \gamma_{p}}\right]-\frac{d S_{0}}{d I} \frac{d I}{d \gamma_{p}}\right) S_{0}-\left(E\left[S_{1}\right]-S_{0}\right) \frac{d S_{0}}{d I} \frac{d I}{d \gamma_{p}}}{S_{0}^{2}} \\
& =\frac{E\left[\frac{d S_{1}}{d I}\right] S_{0}-E\left[S_{1}\right] \frac{d S_{0}}{d I}}{S_{0}^{2}} \frac{d I}{d \gamma_{p}}>0 .
\end{aligned}
$$

Thus, the expected percentage spot price change is increasing in the producers' risk aversion, $\gamma_{p}$, as stated in the proposition. If there is a stock-out, there is no change in the expected spot return, since in this case $\frac{d I}{d \gamma_{p}}=0$.

Next, we turn to the futures risk premium. Consider the impact on the futures risk premium of a change in inventory in the case of no stock-out, when $F=S_{0} \frac{1+r}{1-\delta}$ (using Equations (??) and (6)):

$$
\begin{aligned}
\frac{\partial}{\partial I}\left(\frac{E\left[S_{1}\right]-S_{0} \frac{1+r}{1-\delta}}{S_{0} \frac{1+r}{1-\delta}}\right) & =\frac{\left(E\left[\frac{\partial S_{1}}{\partial I}\right]-\frac{\partial S_{0}}{\partial I} \frac{1+r}{1-\delta}\right) S_{0}-\left(E\left[S_{1}\right]-S_{0} \frac{1+r}{1-\delta}\right) \frac{\partial S_{0}}{\partial I}}{S_{0}^{2} \frac{1+r}{1-\delta}} \\
& =\frac{S_{0} E\left[\frac{\partial S_{1}}{\partial I}\right]-E\left[S_{1}\right] \frac{\partial S_{0}}{\partial I}}{S_{0}^{2} \frac{1+r}{1-\delta}}<0,
\end{aligned}
$$

since $E\left[\frac{\partial S_{1}}{\partial I}\right]<0$, and $\frac{\partial S_{0}}{\partial I}>0$. Since $\frac{d I}{d \gamma_{p}}<0$, the futures risk premium is increasing in producer risk aversion $\left(\gamma_{p}\right)$ if there is no stock-out: $\frac{d \frac{E\left(S_{1}\right)-F}{F}}{d \gamma_{p}}>0$.

Next, consider the case of a stock-out. Now, the spot price in period 0 and expected spot price in period 1 stay constant. In this case, the futures price can be written: $F=S_{0} \frac{1+r}{1-\delta}-\lambda \frac{1+r}{1-\delta}$. The futures risk premium is then:

$$
\frac{E\left[S_{1}\right]-F}{F}=\frac{E\left[S_{1}\right]-S_{0} \frac{1+r}{1-\delta}+\lambda \frac{1+r}{1-\delta}}{S_{0} \frac{1+r}{1-\delta}-\lambda \frac{1+r}{1-\delta}}
$$


From Equation (10), we have that:

$$
\begin{array}{r}
\left(E\left[\Lambda S_{1}\left(I^{*}\right)\right]-\left(S_{0}\left(I^{*}\right)-\lambda\left(I^{*}\right)\right) /(1-\delta)\right)=\frac{\gamma_{p} \gamma_{s}}{\gamma_{s}+\gamma_{p}} \sigma_{s}^{2} Q_{1} \\
\mathbb{1} \\
Q_{1}^{2 / \varepsilon}\left(E\left[\Lambda S_{1}\left(I^{*}\right)\right]-\left(S_{0}\left(I^{*}\right)-\lambda\left(I^{*}\right)\right) /(1-\delta)\right)=\frac{\gamma_{p} \gamma_{s}}{\gamma_{s}+\gamma_{p}} k Q_{1} .
\end{array}
$$

First consider the derivative of $\lambda$ with respect to $\gamma_{p}$ :

$$
\begin{gathered}
\frac{2}{\varepsilon} Q_{1}^{2 / \varepsilon-1}(1-\delta) \frac{d I}{d \gamma_{p}}\left(E\left[\Lambda S_{1}\left(I^{*}\right)\right]-\left(S_{0}\left(I^{*}\right)-\lambda\left(I^{*}\right)\right) /(1-\delta)\right)+\ldots \\
Q_{1}^{2 / \varepsilon}\left(\frac{\partial E\left[\Lambda S_{1}(I)\right]}{\partial I} \frac{d I}{d \gamma_{p}}-\frac{\partial S_{0}(I) /(1-\delta)}{\partial I} \frac{d I}{d \gamma_{p}}+\frac{d \lambda}{d \gamma_{p}} /(1-\delta)\right)=\frac{\gamma_{s}^{2}}{\left(\gamma_{s}+\gamma_{p}\right)^{2}} k Q_{1}+\frac{\gamma_{p} \gamma_{s}}{\gamma_{s}+\gamma_{p}} k \frac{d I}{d \gamma_{p}}(1-\delta) .
\end{gathered}
$$

Since in a stock-out $\frac{d I}{d \gamma_{p}}=0$, we have that

$$
\frac{d \lambda}{d \gamma_{p}}=\frac{(1-\delta) \gamma_{s}^{2}}{\left(\gamma_{s}+\gamma_{p}\right)^{2}} k Q_{1}^{1-2 / \varepsilon}>0
$$

Given this, the derivative of the futures risk premium with respect to producers' risk aversion in the case of a stock-out is:

$$
\frac{d}{d \gamma_{p}} \frac{E\left[S_{1}\right] \frac{1-\delta}{1+r}-S_{0}+\lambda}{S_{0}-\lambda}=\frac{\frac{d \lambda}{d \gamma_{p}}\left(S_{0}-\lambda\right)+\left(E\left[S_{1}\right] \frac{1-\delta}{1+r}-S_{0}+\lambda\right) \frac{d \lambda}{d \gamma_{p}}}{\left(S_{0}-\lambda\right)^{2}}=\frac{E\left[S_{1}\right] \frac{1-\delta}{1+r} \frac{d \lambda}{d \gamma_{p}}}{\left(S_{0}-\lambda\right)^{2}}>0,
$$

since $\frac{d \lambda}{d \gamma_{p}}>0$.

By the symmetry of the equilibrium condition (Equation (29)) it is clear that all the above statements regarding producer risk aversion hold also for speculator risk aversion. That is, $\frac{d I}{d \gamma_{s}}<0, \frac{d \frac{E\left(S_{1}\right)-F}{F}}{d \gamma_{s}}>0, \frac{d}{d \gamma_{s}} \frac{E\left[S_{1}\right]-S_{0}}{S_{0}}>0$. Thus, equilibrium inventory holding is decreasing in producer and speculator risk aversion, while expected spot and futures returns are increasing.

\section{Endogenizing the Pricing Kernel}

The model presented here generalizes the model in the main text of the paper. In particular, we endogenize the pricing kernel and the commodity demand function by specifying consumers' preferences over the consumption of commodity and "other" goods.

\section{C.1. Consumers.}

Let consumers' preferences be given by:

$$
V=u\left(C_{0}, Q_{0}\right)+\beta E_{0}\left[u\left(C_{1}, Q_{1}\right)\right]
$$

where $C_{t}$ is the consumption of other goods (the numeraire goods), while $Q_{t}$ the endogenous equilibrium commodity supply. The felicity function is of the constant elasticity of substitution (CES) form:

$$
u(x, y)=\frac{1}{1-\gamma}\left\{\left(x^{(\varepsilon-1) / \varepsilon}+\omega y^{(\varepsilon-1) / \varepsilon}\right)^{\varepsilon /(\varepsilon-1)}\right\}^{1-\gamma}
$$

where $\varepsilon$ is the intratemporal elasticity of substitution and $\gamma$ is the level of relative risk aversion. From the intratemporal FOC, 
we have that the equilibrium commodity spot price $S_{t}$ is given by:

$$
S_{t}=\omega\left(\frac{C_{t}}{Q_{t}}\right)^{1 / \varepsilon}
$$

The consumers own a Lucas tree producing the numeraire good $A_{t}$, as well as the commodity producing firms. The consumers must, however, hire managers to manage the firms (their inventory and hedging decisions). Consumers can also invest in the commodity futures markets, through intermediaries which we term 'speculators.' These speculators act as arbitrageurs between the commodity futures market and the equity market. The equity market consists of the commodity producing firms and the claim to the Lucas tree producing the other goods $\left(A_{t}\right)$. Investing in the commodity futures is costly to the consumers as the speculators require compensation for their skill. Therefore, the consumers' equilibrium consumption of other goods will equal $C_{t}=A_{t}-$ 'The Cost of Investing in Commodity Funds'.

\section{C.2. Producers.}

The managers, as in the model in the main text, act competitively and maximize firm value subject to a variance penalty. The latter is reduced form for contracting frictions that leaves the manager with excess exposure to the uncertainty of period 1 firm earnings. Thus, the manager's objective function and first order conditions are as given in Equations (2), (3), and (4). We do not model the managers' consumption choices, but instead argue that this is a reasonable abstraction as there are very few managers relative to the total population (The total number of firms in our sample is 531). Even if these individuals are wealthier than average, their consumption is a minuscule component of aggregate consumption.

\section{C.3. Speculators.}

Commodity fund managers, as in the model in the main text, act competitively and maximize their earnings (the abnormal payoff $\left.E\left[\Lambda\left(S_{1}-F\right)\right]\right)$ subject to a penalty for the variance of their payoffs. The latter is reduced form for agency concerns that limit the capital flows to these funds. In equilibrium, the payoff to the consumer from owning the commodity producing firm and from holding a share in a commodity futures fund must be the same. Therefore, for the consumer the NPV of a marginal investment in a commodity futures through a fund must in equilibrium be zero: $E\left[\Lambda\left(S_{1}-F\right)\right]-\operatorname{cost}=0$. Therefore, the aggregate fund manager compensation is $h_{s}^{*} E\left[\Lambda\left(S_{1}-F\right)\right]$. Given the optimal position in futures contracts from Equation (8), we have that the equilibrium aggregate $\operatorname{cost}$ is $\frac{E\left[\Lambda\left(S_{1}-F\right)\right]}{\gamma_{s} \sigma_{s}^{2}}$. Note that the total gain of arbitrageurs in the futures market equals the total loss incurred by the producers. The reason the consumers are willing to incur this cost is the utility gain from moving to more optimal $Q_{0}$ and $Q_{1}$ as the futures price affects the commodity producers' inventory decisions.

The cost is incurred at time zero. Thus, time 0 consumption is $A_{0}-\frac{E\left[\Lambda\left(S_{1}-F\right)\right]^{2}}{\kappa \sigma_{s}^{2}}$, while time 1 consumption is $C_{1}=A_{1}$. In equilibrium, $E\left[\Lambda\left(S_{1}-F\right)\right]=\frac{\gamma_{p} \gamma_{s}}{\gamma_{s}+\gamma_{p}} \sigma_{s}^{2} Q_{1}$, so $\frac{E\left[\Lambda\left(S_{1}-F\right)\right]}{\gamma_{s} \sigma_{s}^{2}}=\frac{1}{\gamma_{s}}\left(\frac{\gamma_{p} \gamma_{s}}{\gamma_{s}+\gamma_{p}}\right)^{2} \sigma_{s}^{2} Q_{1}^{2}$. The risk-free rate is set by $r=1 / E[\Lambda]-1$ as before. Further substituting out $\sigma_{s}^{2}$, we have that

$$
\text { Aggregate cost }=\frac{1}{\gamma_{s}}\left(\frac{\gamma_{p} \gamma_{s}}{\gamma_{s}+\gamma_{p}}\right)^{2} \omega^{2} Q_{1}^{2(1-1 / \varepsilon)} k,
$$

where $k$ is a positive constant defined earlier. Thus, both the supply of the commodity and consumption of other goods are affected by the combination of hedging demand and limits to arbitrage:

$$
C_{0}=A_{0}-\frac{1}{\gamma_{s}}\left(\frac{\gamma_{p} \gamma_{s}}{\gamma_{s}+\gamma_{p}}\right)^{2} \omega^{2} Q_{1}^{2(1-1 / \varepsilon)} k
$$

It is clear then that the marginal rate of substitution for consumers is explicitly a function of both inventory and the risk 
aversions/costs:

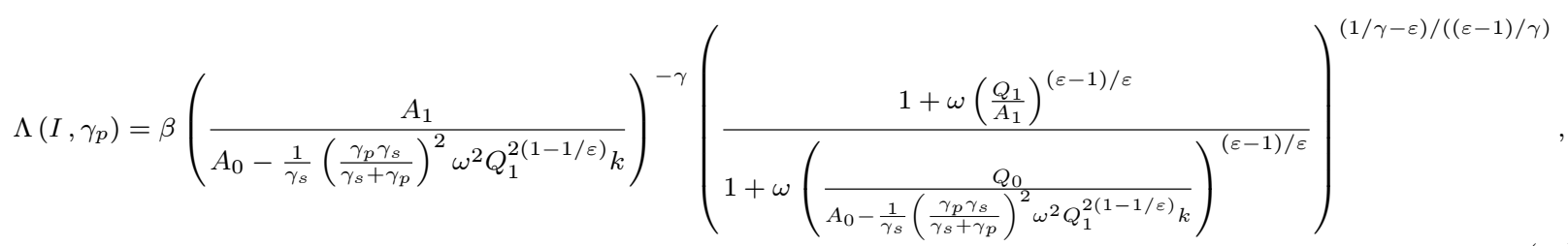

where we have substituted in the expressions for consumption of other goods, $C_{0}=A_{0}-\frac{1}{\gamma_{s}}\left(\frac{\gamma_{p} \gamma_{s}}{\gamma_{s}+\gamma_{p}}\right)^{2} \omega^{2} Q_{1}^{2(1-1 / \varepsilon)} k$ and $C_{1}=A_{1}$.

This analysis shows that the frictions assumed in this paper (limits to arbitrage and producer hedging demand) in general equilibrium also affect the consumption of other goods and the equity market pricing kernel. Thus, the covariance term in Equation (11) is affected, not only through the volatility of the commodity price as in the partial equilibrium model in the main text, but also through the dynamics of the pricing kernel $(\Lambda)$. However, the identifying component of the frictions lies in the risk compensation of the second term in Equation (11), which is related to the magnitude of desired hedging and the total volatility (including any idiosyncratic components) of the futures price.

Since changes in producer and speculator variance aversion coefficients affect the pricing kernel, and thus the risk-free rate $(r=1 / E[\Lambda]-1)$, we cannot in general sign the effect of a change in these parameters on inventory and the futures risk premium. In particular, in calibrated versions of the model, we for some parameter configurations obtain that inventory decreases in response to an increase in producer fundamental hedging demand. However, the implications for the futures risk premium remained robust in these calibrations (results not reported, but available upon request). 